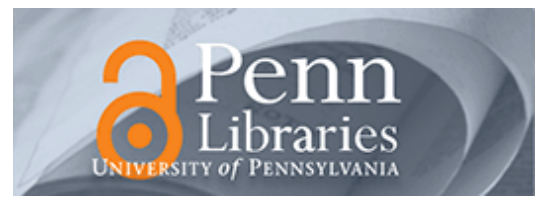

\title{
Studies in Visual Communication
}

Volume 6

Issue 3 Fall 1980

Article 3

1980

\section{An Analysis of the Nazi Film "Hitlerjunge Quex"}

Gregory Bateson

\section{Recommended Citation}

Bateson, G. (1980). An Analysis of the Nazi Film "Hitlerjunge Quex". 6 (3), 20-55. Retrieved from https://repository.upenn.edu/svc/vol6/iss3/3

This paper is posted at ScholarlyCommons. https://repository.upenn.edu/svc/vol6/iss3/3

For more information, please contact repository@pobox.upenn.edu. 


\section{An Analysis of the Nazi Film "Hitlerjunge Quex"}




\section{An Analysis of the Nazi Film "Hitlerjunge Quex" Gregory Bateson}

Editors' Note: This article was completed by Gregory Bateson in 1945 as part of a multidisciplinary research effort called "The Study of Culture at a Distance" (see Mead and Metraux 1953 and Metraux 1980 for a description of the projects). Until now only excerpts of the work have appeared in print (Bateson 1943, 1953). The first three reels of Quex (approximately 45 minutes) with Bateson's analytic titles are available for rent from the Museum of Modern Art Film Library, 11 West 53rd Street, New York, N.Y. 10019. All illustrations in this article are frames from the film that were added by the editors. Frame enlargements are by courtesy of the Museum of Modern Art. The editors wish to acknowledge the assistance of Mary Corliss, Stills Archivist, Museum of Modern Art.

\section{- Bateson, Gregory}

1943 Cultural and Thematic Analysis of Fictional Films. In Transactions of the New York Academy of Sciences. Pp. 72-78.

1953 An Analysis of the Nazi Film Hitlerjunge Quex. In The Study of Culture at a Distance. Mead and Metraux, eds. Pp. 302-316. Chicago: University of Chicago Press.

- Mead, Margaret, and Rhoda Metraux, eds.

1953 The Study of Culture at a Distance. Chicago: University of Chicago Press.

- Metraux, Rhoda

1980 The Study of Culture at a Distance: A Prototype. American Anthropologist, 82(2):362-373.

Gregory Bateson (1904-1980) was a naturalist, ethnographer, and pioneer researcher into human and animal communication. Among his many achievements are the "double-bind" hypothesis about the origins of schizophrenia; his collaborative studies with Margaret Mead on Balinese nonverbal communication; and his work in cybernetics.

\section{Introduction}

This essay is an experiment in film analysis, and it consists in the detailed examination of a single Nazi film, Hitlerjunge Quex, which was released in Berlin on September 19,1933 . Other workers have applied other scientific methods to the analysis of film material; in particular, Dorothy Jones (n.d.) has examined American films statistically, noting especially the frequencies of various types of sociological events in film plots, and comparing these with the frequencies of the same events in real life, thus obtaining a picture of how life is distorted, exaggerated, or suppressed on the screen. Siegfried Kracauer (1942) has used another approach in the analysis of German newsreels and documentary films. He has examined a considerable bulk of these films from a technical point of view, using the contrapuntal relations between visuals, speech, and sound to give a general picture of Nazi propaganda methods and the special view of life which these methods express.

The present analysis differs from both of these in that it is concerned with the weaving of themes within a single fictional film. The purpose, too, of the present analysis is different, in that where Dorothy Jones asked, "How does what is shown on the screen differ from real life?", and Kracauer asked, "What are the Nazis trying to say on the screen, and how do they say it?", the present research asks, "What sort of people are the Nazis?"

The question has many sorts of importance. Wherever, either in war or after the war, we are concerned with Germany, our actions must be guided by an understanding of what sort of people the Nazis are and how Nazism is related to the character and culture of pre-Nazi Germany. Our whole intelligence service depends upon an ability to guess at German motivation, and when, for example, we analyze German radio propaganda, treating it as an indication of the state of the German morale, our analysis rests in the end upon certain assumptions about what sort of people the propagandists are. Equally, if we want to estimate the effect of Nazi propaganda in the United States or in South America, or in some other nonGerman region, we need to know what sort of people the Nazis are.

In this latter case the Nazi character is, of course, only one element in a complex situation, and even to estimate the direction of the effect of Nazi propaganda we shall need a similar study of character and culture in the affected country. With such a double knowledge of the nature of Nazism and of the propagandized population we will, however, be able to tell exactly what sort of susceptibility the population may have to the Nazi creed and which parts of the creed are likely to appeal to them.

At the present time the sciences of anthropology and psychology are engaged in devising the techniques for precisely this sort of description of the various sorts of character appropriate to and implicit in the cultures of different peoples (Bateson 1942; Erikson 1942; Gorer 
1942; Mead 1943). The present study is therefore intended to make two sorts of contribution: first, a contribution to the methods of analyzing human behavior and human culture, and second, a more specific contribution to our understanding of Nazism.

The film which is here analyzed has three principal connections with Nazism: (1) Nazis are shown on the screen, (2) the film was made by Nazis, and (3) the film was used to make Nazis, that is, to induce a Nazi frame of mind in the audience. Since we are interested to know the psychology of this Nazi frame of mind, we are naturally concerned chiefly with the second and third of these connections. The picture of Nazis which the filmmakers put on the screen cannot be taken as an objective or ethnological record of Nazi behavior, being no doubt subject to all sorts of distortion, exaggeration of some aspects and suppression of others. The camera-and especially the motion picture camera - can lie freely about whatever passes in front of the lens, but inasmuch as the film was made by Nazis and used to make Nazis, we believe that at a certain level of abstraction the film must tell us the truth about Nazism.

A painting, a poem, or a dream may give an exceedingly false picture of the real world, but insofar as the painter or the dreamer is an artist, insofar as he has complete control of his medium, the artistic product must of necessity tell us about the man himself. In the same way this film, insofar as it is an integrated work of art-and we shall see that it is very highly integrated - must tell us about the psychology of its makers, and tell us perhaps more than they intended to tell.

We shall not in the course of this analysis ask whether the filmmakers were conscious or unconscious of what they put into the film, but since this question is commonly raised by those who approach the analysis of propaganda for the first time, and since the notion of unconscious mental processes is difficult to grasp, it is necessary to make clear the assumptions about the unconscious upon which this analysis is based.

It is assumed that the filmmakers continually put together details which appeared to them to be artistically appropriate, and further, that in many cases what was implied by such montage or editorial arrangement was consciously meant. In other cases, no doubt, the filmmakers did not stop to ask what was implicit in the way in which they put the details together, but were only conscious of their appropriateness. In such cases we assume that they liked the symbolic implications of what they had done, at least so long as these implications did not come to their conscious attention.

It is not possible, however, to tell in any given case whether the filmmakers were fully conscious, partially conscious, or unconscious of what they were doing, and therefore this question is not asked in the analysis. There are several passages in the film where it appears that the script writers had at least a parlor acquaintance with Freudian psychology. In one case, for example, we are shown on the screen an incident in which a Communist thrusts a banana into a girl's mouth, and this incident fails to achieve spontaneity. It is as if the filmmakers departed from their own methods of artistic creation to introduce a piece of Freudian symbolism almost by recipe. If they have done this once, they may have done it many times in the course of the film, and there are no criteria which would enable us to tell whether a given detail or combination of details was spontaneous or calculated. It is not possible ever to determine whether the filmmakers were conscious of the implications of the various themes in the film, and we shall therefore refrain from asking this question. Those who feel that the analysis leans toward overinterpretation are recommended to look for the sort of "artistic appropriateness" which probably appealed to the filmmakers and then to consider what the logical implications of such appropriateness are.

Another feature of this analysis which may be confusing to the nontechnical reader concerns the relationship between psychological and anthropological techniques. A film is not the idiosyncratic production of a single artist working by himself and for himself; it is created by a group of filmmakers working in close cooperation and with an eye on a popular audience. Therefore it has been assumed in the analysis that what seemed artistically appropriate to the filmmakers was also psychologically germane to Nazism- that the unconscious implications of the film were also themes implicit in Nazism as a whole, whether or not Nazis were or are generally conscious of them. In the analysis, the film has been treated not merely as an individual's dream or work of art, but also as a myth. We have applied to it the sort of analysis that the anthropologist applies to the mythology of a primitive or modern people.

The anthropologist has an essential touchstone by which he tests his interpretations of any given myth or record of behavior. His analysis is not confined to that one item; he has in his notebooks many other myths, many descriptions of the ritual behavior and the daily life of the people whom he is studying, and he is able always to take each detail of his interpretation of the myth and to compare it with the wider background of other data upon that culture. If the interpretation is correct, he will be able to find numerous other instances in the culture which the same interpretation would fit; and if the interpretation is incorrect, he will be able to find instances in the culture to disprove it. Still more important, he will be able to say immediately of many possible interpretations: "No; this is wrong. This interpretation does not fit the people whom I knew."

We have tried, in the present analysis, to create a touchstone of this kind. Before beginning the analysis of this film, and during the course of this analysis, the analyst has been cooperating in a more general study of German and Nazi culture (Erikson 1942). This work has been done under the auspices of the Council of Intercultural Relations, and has consisted in a series of detailed 
anthropological interviews with a number of social scientists $^{1}$ who have had intimate experience of German culture.

These interviews have been of two sorts. The majority were directed toward discovering the major themes of German culture. The social scientists were asked in an anthropological interview to discuss their own experiences in Germany - especially their experiences as children in a German family setting. Simultaneously they were asked to comment as social scientists upon these experiences, their significance, and the degree to which they might be regarded as typical. These interviews were recorded verbatim.

A further series of interviews was used to check the specific interpretations arrived at in this analysis. The social scientists were invited to a showing of the film and were invited to comment on the interpretation. As a result of these various comments, the analysis has been revised in many ways, but since not all the comments made have involved reinterpretation of the analysis, the writer alone is responsible for the interpretations which are here offered.

Last, it is necessary to stress that this analysis makes rather unusual assumptions about the nature of propaganda. In most content analyses the various statements in a piece of communication-for example, a film or a statistical picture of the propagandic content of the communication. ${ }^{2}$ In such an analysis, in its extreme form, Communist sentiment uttered by the Communists in this film would have to be counted as items of Communistic propaganda, which would be absurd. In the present analysis, however, the emphasis will lie on the context of each event shown on the screen, the film as a whole will be regarded as a single psychological or artistic unit, and each event on the screen will be seen as set in the context of the film as a whole.

This means that we shall attribute propagandic effect to the plot and its structure rather than to isolated details. We shall assume that what the audience learns from the film is not so much to ape the explicit sentiments of the hero nor to adopt his opinions, but rather that they acquire the ways of thought of the propagandist. We are interested in knowing what sort of people the Nazis are, and in order to find this out we shall assume that the audience learns from the film to accept as artistically appropriate those things which the filmmaker has put together-in fact, that the audience consciously or unconsciously will acquire Nazi habits of thought.

\section{Reasons for the Selection of This Film}

For this type of analysis it was essential that the film selected should have certain characteristics.

1 It should show both the Nazis and their enemies on the screen. There are many propagandic films intended to promote a Nazi frame of mind which achieve this end by indirect means. Faehrmann Maria (1935), for example, contains an excellent symbolic expression of the Nazi attitudes toward death, but the whole film is set back in the realm of fantasy and the Nazis themselves do not appear on the screen. Friesennot similarly contains a great deal of material which expresses the Nazi attitudes toward sex and the Nazi notions of conflict between the generations, but this story is set in Russia and deals with an old German colony invaded by Bolsheviks; Nazism does not appear on the screen and, therefore, though the equation is obvious, it is not possible to say definitively that the younger generation of these colonial Germans stands as a symbol of Nazism.

To make all these other films available for analysis it was first necessary to establish the basic symbolic equations, and this could best be done by analyzing a film which showed the Nazis and their enemies explicitly labeled on the screen. Such a film makes it possible to dissect out the relationship between these two fixed points and the whole range of phenomena-parenthood, adolescence, maturity, cleanliness, sex, aggression, passivity, and death — which are embraced by the Nazi view of life.

Few German films meet this requirement. On Horst Wessel's birthday (October 9) in 1933, Dr. Goebbels addressed a gathering of German film producers and his speech contained the following passage:

We National Socialists do not particularly care for the mere fact that our S.A. marches over the stage or the screen. Its realm is in the street. But when somebody approaches the solution of National Socialist problems artistically, he must realize (sich klar sein) that in this case, too, art does not come from wishing (wollen) but knowing how (kennen). Even an ostentatiously presented National Socialist conviction (Gesinnung) cannot make up for the lack of true art, by a long way. The National Socialist government never has demanded that S.A. films be produced. On the contrary: it sees a danger in too many. But when a company nevertheless approaches the presentation (Darstellung) of the values arising from life (Erlebniswerte) of our S.A. or the National Socialist idea, then this film must be of first-class artistic quality. Therefore it is not easy (bequem) but, on the contrary, extremely difficult because [the filmmakers are] responsible to the entire nation, to make an S.A. film. The task one undertakes there demands staking (Einsatz) of all the best (alle besten) talent, and only truly great artists can accomplish it. National Socialism is under no circumstances a guarantee of approval (Freibrief) for artistic failure. On the contrary: the greater the idea that is being presented, the greater the artistic demands that must be made of it. [Kalbus 1935]. 
What the effects of this speech were we cannot judge, but in any case very few films of this sort have been made. There have been documentaries (e.g., Triumph des Willens, 1934; Fuer Uns, 1937; Sieg im Westen) dealing with various sorts of Nazi ceremonial, newsreels, and the films of conquest which were made officially, but the only available fictional films containing the Nazi uniform were those produced in the early years of Nazism. These included S.A. Man Brandt (1933), Hans Westmar (1933), Blutendes Deutschland (1933), and Ich fuer Dich (1934).

2 For this type of analysis, the film should contain a large mass of material on the German family. This criterion was introduced for practical reasons. It so happens that in anthropology and psychology the most effective techniques for the description of human character have been based on analysis of family life, especially of the parentchild relationship. It would have been possible-indeed, in anthropology, we are often compelled to do this- to have performed similar analyses outside the family setting. But such analyses are less vivid and are less useful in comparative studies of more than one culture. If it is possible to refer the peculiarities of, say, religious behavior back to the family, then comparison between one culture and another becomes comparatively easy because, although the elements present in one religious system may be very different from those present in another, the basic elements of the family are almost universal and only differently arranged in different parts of the world.

Actually, the Nazis have used the family setting as a springboard for their propaganda in several films and even in Mein Kampf. ${ }^{3}$

3 The film should be a good film in two senses: first, the acting should be good enough to give an accurate impression of the emotions intended; and second, the film should be a close-knit artistic unit so that the themes and incidents of the plot can be readily seen in relation to the film as a whole.

4 The film should carry the imprimatur of official Nazi approval and should have been successful with Nazi audiences. It is true that every film is a product of cooperative work and therefore must show a cultural norm rather than individual idiosyncracies, but this criterion is introduced as a further guarantee of Nazi cultural normality. The festivities at the premiere of this film and the fact that the film is said to have been kept on the commercial screens for an unusually long time are a proof of official Nazi approval, but, unfortunately, we have no data on audience reactions. The film Hitlerjunge Quex amply satisfies these criteria.

\section{Basic Data on the Film}

The film Hitlerjunge Quex was shown to Hitler at the Ufapalast in Munich on September 12, 1933, and had its premiere in Berlin, at the Ufapalast am Zoo, a week later. This premiere was made into a great occasion with a symphony by Brückner and a speech by the Youth Leader, Baldur von Schirach. ${ }^{4}$

The print of the film which was used for this analysis was obtained from the Reichsfilmarchiv, in 1938, by the Museum of Modern Art Film Library, and in the analysis a mimeographed transcript of the film, also obtained from the Reichsfilmarchiv, has been used.

Length: The film is nine reels in length and lasts about 1 hour and 40 minutes.

Titles: The film carries credit titles in German, which are here reproduced in translation:

a UFA presents (zeigt)

b "Hitlerjunge Quex"

c A film of the spirit of sacrifice (Opfergeist) of German youth.

d Produced under the auspices (Protektorat) of the Youth Leader of the German Reich, Baldur von Schirach.

e After the novel by-K. A. Schenzinger Script-K. A. Schenzinger

B. E. Luethge

f Camera . . . . . . . . . . . . . . Konstantin Irmen-Tschot Setting ........................ Benno von Arent Sound ...................... Walter Tiaden

g Music ..................... Hans-Otto Bergmann Words of Hitler Youth Song ......... Baldur von Schirach

h Cast:

Father Voelker .................... Heinrich George Mother Voelker . . . . . . . . . . . . . . . . . . Berta Drews Heini ........................... Hitler boy

i Stoppel ...................Hermann Speelmanns Gerda . . . . . . . . . . . . . . . . . . . Rotraut Richter Wilde .............................Karl Heixner

j District Leader Kass ................. Claus Clausen Fritz Doerries ...................... a Hitler boy Ulla Doerries ..................... Hitler girl

k Hospital sister ................... Franziska Kinz Grundler ................... Hans Ramspott Franz ....................... Hans Richter

I Boys and Girls of the Berlin Hitler Youth

m Director: Hans Steinhoff

n Producer: Karl Ritter 


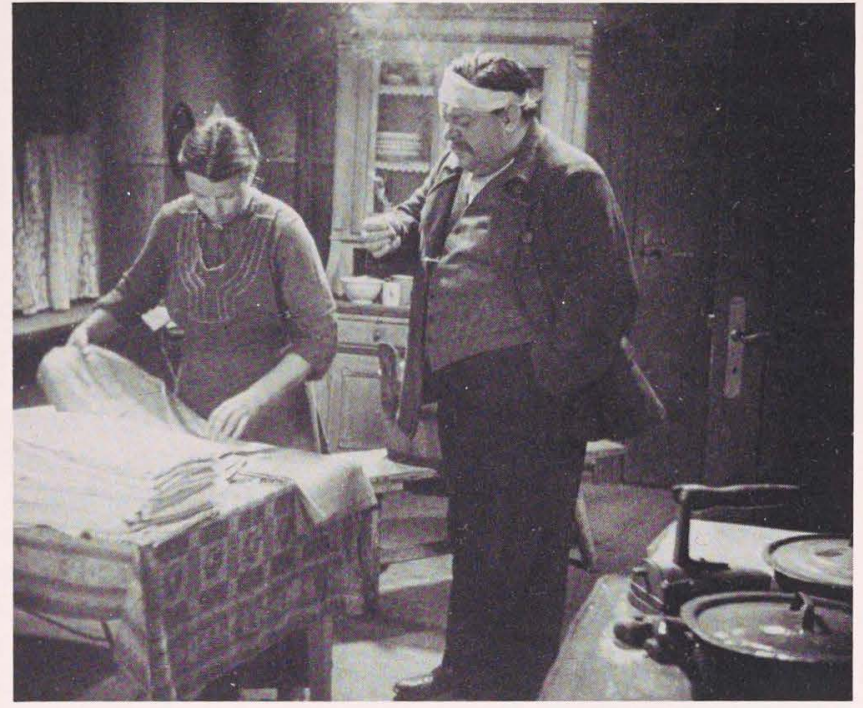

Figure 1 Heini's father begging his wife for beer money.

o Prepared with Klangfilm apparatus Afifa-Sound-Track

p Ufa

q End

\section{Summary of the Plot}

The five analyses which follow will all be in part selective summaries of the film, differing from each other in the type of selection involved. To orient the reader in these analyses, it is necessary to provide at this stage a somewhat less selective summary. All summaries are necessarily in some measure selective and therefore fall short of objectivity. The present summary is, however, objective in the sense that each statement is objectively true, but the summary as a whole was written after the study of the film had been completed and is specifically designed to enable the reader to follow the steps of the various analyses.

The hero of this film is Heini Voelker, a preadolescent boy, the son of a violent father and a drudge mother. His parents are of the lower middle class and have fallen in the world as a result of the inflation and the father's war wounds.

Two hungry Communist boys steal apples from a vendor in the street, and Heini's father intervenes in their favor when the vendor talks about putting them in prison. In the crowd there is a sinister Communist agitator, Wilde, who makes a speech and provokes a riot in which Heini's father hurts himself, stumbling over the curbstone. He is helped home by Stoppel, an organizer of Communist youth. The Voelkers live in a poor Communist district of Berlin. Stoppel helps the mother to dress the father's wound.

The father asks the mother for money to get some beer. She says that she has no money, and a violent scene follows, the father ransacking all the containers in the house in search of the mother's hiding place. At this moment Heini returns home from his work in a printing shop (arriving so that we see the climax of the scene between the parents through the eyes of the son). At the printing shop Heini had received a tip of 1 mark. He secretly gives this mark to his mother. She gives it to the father, who then goes off to get his beer. Stoppel is impressed by Heini's character and contacts him with a view to enlisting him in the Communist Youth International. (Figures 1, 2.)

After Stoppel leaves, the mother opens the window and lets in the mechanical music of a merry-go-round at the neighboring fair. Heini is thus reminded of a wonderful knife which he has seen in a lottery in one of the sideshows. He asks his mother to enter this lottery, which he is sure that he will win. She gets money from the hiding place in the coffee grinder and gives it to him. Heini goes to the lottery and loses. (Figure 3.)

Stoppel appears at Heini's elbow, comforts him, and invites him to join a hike of the Communist Youth on the following day. Heini accepts.

On the hike, Heini sees the Hitler Youth, a company of whom are hiking on the same train to the same woods. He is disgusted by the gross behavior of the "Communists" and especially by a kiss which Gerda, one of the Communist girls, forces upon him. Finally he wanders in the 


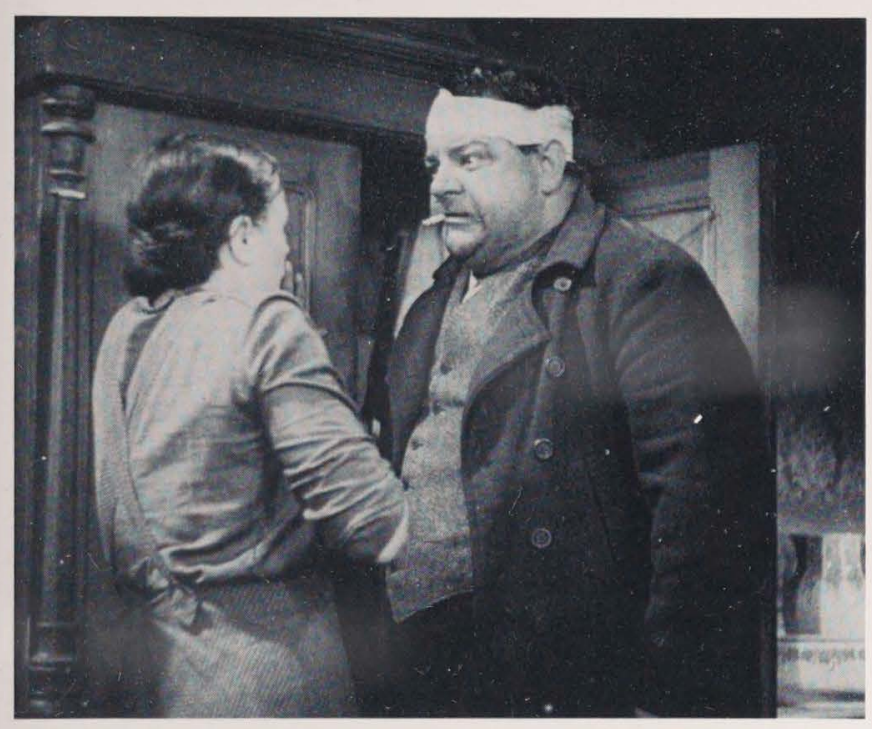

Figure 2 Heini's father demanding pennies for beer.

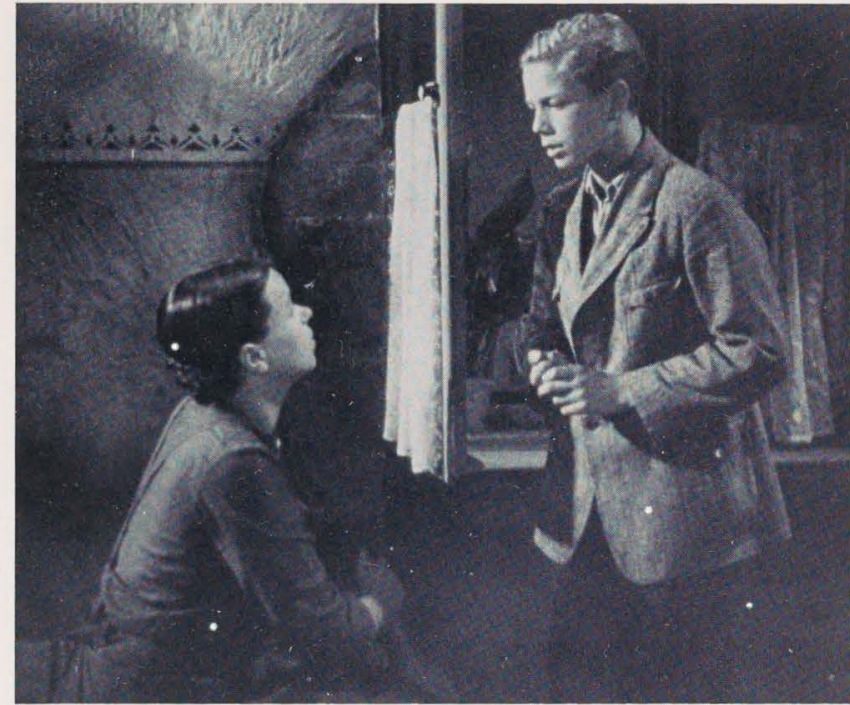

Figure 3 Heini and his mother listening to the merry-goround music while Heini begs for money for the lottery. dark, away from the Communist camp, till he hears the "Hitler Youth Song" coming from the Nazi camp. He gazes through the buses at the Nazis who are celebrating the summer solstice. The Nazis find him and accuse him of spying; Fritz, the boy leader of one of the Nazi troops, sends him away. The voice of Ulla, Fritz's sister, is heard saying that he might have become a convert, but by this time Heini has sadly gone away. He sleeps by himself on the bare ground, and next morning, after watching the Nazis with longing eyes, he goes home to his mother. (Figure 4.)

He tells her he was with the Nazis and they were not so bad; they were wonderful. His mother is worried but not angry with him. She even lets him sing the "Hitler Youth Song" (without warning him that his father is in the next room). The father hears the song and comes in, furious. He compels Heini to sing the "Internationale," boxing his ears while he sings.

Next day at school Heini again meets Gerda and avoids her advances. He approaches Fritz and is invited by him to supper. Gerda meanwhile has been told by Stoppel to vamp Grundler, a weak Nazi boy, and while Fritz and Heini go off to supper, Gerda and Grundler go off to seek "Turkish Delight" at the fair.

At supper in this middle-class home, Fritz and Ulla ask Heini to come to the opening of their new Nazi clubroom (Heim). Heini hesitates because he has no key with which to return home after the meeting. Finally he accepts when put on his mettle by Fritz.
The father, meanwhile, has been persuaded by Stoppel to sign Heini into the Communist Youth. When Heini comes home, his father at once informs him that he is to go that night to the Communist Local. Heini says, "Do I get a house key?", and the father says, "Of course-you are now a grown man, and a grown man has a house key." The father then makes a long, friendly speech to Heini about the difficulties of life and how "you young ones must help us older people." Heini is almost in tears and says later to his mother, "Father is not so bad-I cannot lie to him - he gave me a house key." He is determined, however, not to go to the Communist meeting.

He goes out that evening but meets Stoppel, who draws him aside into a doorway and tells him that the Communists are going to raid the Nazi clubroom and that he is to help in the raid. Heini manages to slip away without taking an active part, but when the police come he is picked up and taken to the police station.

The police tell him to "go home to Mother." The Nazis think he has set the Communists onto them, and as he leaves the police station, they accuse him of treachery.

(We are given no further information about the events of that night, nor do we see Heini use the house key to return to the bosom of his family.)

Next day Stoppel tells Heini that he was a hero because he did not tell anything to the police and that tonight they will get dynamite from the Communists' cache in the Marschstrasse and blow up that nest of Nazis. Heini protests and finally says he will warn the Nazi boys. Stoppel is shocked and tells Heini that that is something which one does "only once in a life," but in the end Stoppel shrugs his shoulders and dismisses the matter. 


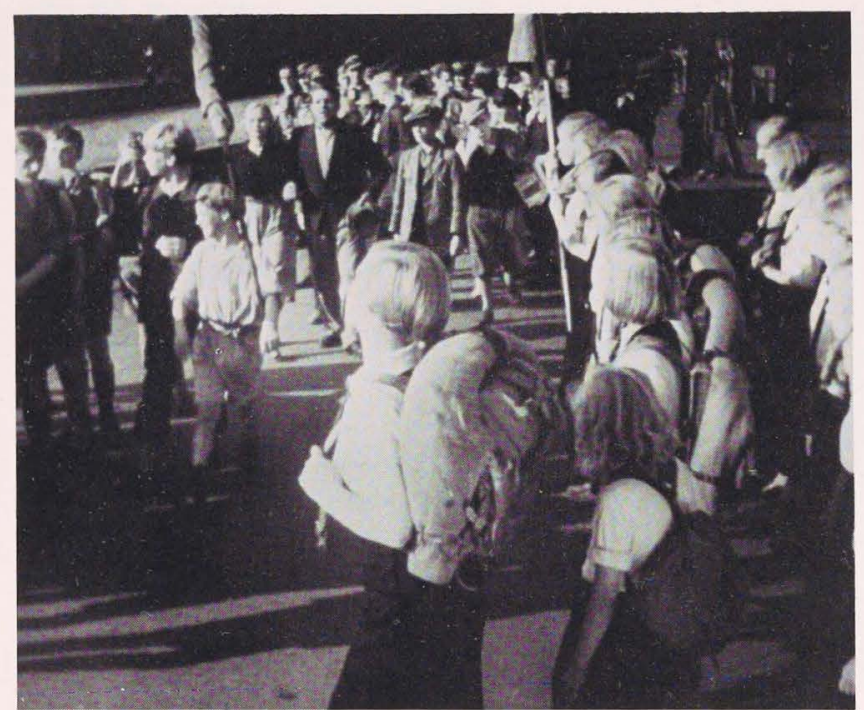

Figure 4 The "disorderly" Communists march past the Hitler Youth at the train station.

When Stoppel leaves, Heini rushes to the telephone to warn Fritz and Ulla. Ulla answers the telephone but Fritz tells her not to listen to that traitor. Ulla is worried by Heini's mention of dynamite, but she obediently hangs up and Heini is left talking into a dead phone. In despair, he tries to persuade the police to interfere, but they again treat him as a child. He then tries to find Stoppel but cannot.

Suddenly, while Heini is at the fair looking for Stoppel, there is a violent explosion - the Nazis have blown up the Communists' cache of dynamite - and Heini starts for home whistling the Youth Song.

Stoppel knows that it is Heini who has betrayed them, and he goes to the Voelkers' home where he finds only the mother. In the conversation which follows, the mother gets at first an impression that Stoppel has killed Heini and later a general fear that the Communists will kill him.

Heini arrives after Stoppel has left and finds his mother in a state of despair. She tries to persuade him to make up with Stoppel but fails in this because Heini is now sure that the Nazis will accept him. Heini goes to sleep on his bed while his mother sits weeping beside him. Finally, she turns on the gas to kill both herself and Heini, and the screen is filled with billowing fumes.
Heini awakes in a hospital. A nurse says, "There is somebody to see you." Heini says, "My mother?", but it is the Nazi boys and Ulla. They give him a uniform and a mirror in which to admire himself. After they have gone the nurse comes, and while she removes the Nazi cap from his head, she tells him that his mother will never come.

While Heini is convalescent, his father and the district leader of the Nazis happen to visit him simultaneously and the question is discussed-"Where does the boy belong?". The Nazi wins this discussion by a verbal trick, and Heini goes to live in a Nazi clubhouse outside the Communist district. Here he meets Grundler, the weak Nazi, and we are shown the contrast between the two boys. Grundler gives Heini the nickname "Quex" (an abbreviation of Quexsilber, "quicksilver"). He resents this and a small fight breaks out among the boys. The fight is quelled by a barked command from the district leader. The leader himself addresses Heini as Quex, and the name sticks.

The Communists are waiting for vengeance, and, in spite of the district leader's opposition, Heini wants to return to the Communist district to distribute leaflets for the 1933 election. Grundler has been falling lower and lower under Gerda's influence, and through Grundler's treachery Stoppel finds out where Heini is staying. We are given to understand that Stoppel is fond of Heini and is wavering in his Communism. He goes to find Heini and makes a last attempt to persuade him to leave the Nazis. Heini is adamant, even against the offer of the original many-bladed knife which Stoppel produces from his pocket. Stoppel goes back to the Communists and with a gesture places the knife on the table. It is picked up by Wilde.

The Nazis are working on leaflets for the 1933 election, and Grundler and Gerda treacherously destroy all the available Nazi leaflets. Fritz has been wounded in an election riot, and Heini and Ulla meet at the door of the room in which Fritz is lying. They go off together to Heini's printing shop, where they work to prepare new leaflets, and when the work is completed Ulla gives Heini a single kiss. Heini then goes out to distribute the leaflets in the Communist district. He is hunted and encircled by the Communists in the darkened streets and takes refuge in one of the tents in the deserted fair.

Accidentally, he touches a mechanical figure of a drummer and the figure starts to beat its drum, thus betraying him. The Communists enter the tent and Heini screams (presumably stabbed by Wilde). The Nazis come (it is now bright daylight) and find Heini dying. The knife lies on the ground beside him. Heini's last words are, "Our flag billows before. . . ." The soundtrack takes up the "Youth Song" and the flag appears on the screen, giving place to marching columns of Hitler Youth.

(Figure 5.) 


\section{Analysis I: Time Perspectives}

In any analysis it is important to determine the sorts of questions which we ask of the material and to set up our analytical frames in such a way that the whole unit which we are examining will not be lost in our attention to details nor the details lost through too much attention to the whole. This dilemma of the wood and the trees can best be resolved by employing a series of different types of analysis. We shall therefore look at this film from three standpoints: first, from far off we shall examine its total climax structure; then, in a somewhat closer inspection, we shall study the characterization of the two political groups and the backgrounds in which they are set; and last, examining the film in detail, we shall study the interactions between the various members of Heini's family.

The climax structure of any work of art is related to those characteristics of the artist which the psychologists call "time perspectives." All peoples must impose sense and coherence on the very complex stream of their experience. They must punctuate this stream so that the relations between events may be meaningful. But the type of sense which different types of peoples impose is known to vary greatly. Some people see themselves as living in a fatalist universe; others see their own behavior as determining the future; and still others believe in a Golden Age, and of these some will put the Golden Age in the past while others imagine it in the near or distant future.

Philosophers may try to choose between these various views of experience, attributing greater or less truth to one or the other, but with this question we are not concerned. We are only asking what sort of view of the past and future, what type of time perspective, a certain political cult had developed in 1933. Probably it is not given to man to determine which of these time perspectives is "true" because the stream of events to which the perspective is applied includes not only outside events but also his own behavior. His own behavior will be guided by his own time perspective, and thus whatever that time perspective may be, the total stream as he sees it will acquire the appropriate structure.

But because his behavior is shaped in terms of his time perspective, it becomes important to study this. A statement of a man's time perspective is a way of describing his character. ${ }^{5}$

The time perspective of this film is summarized for us in the "Hitler Youth Song," whose words were composed by Baldur von Schirach:

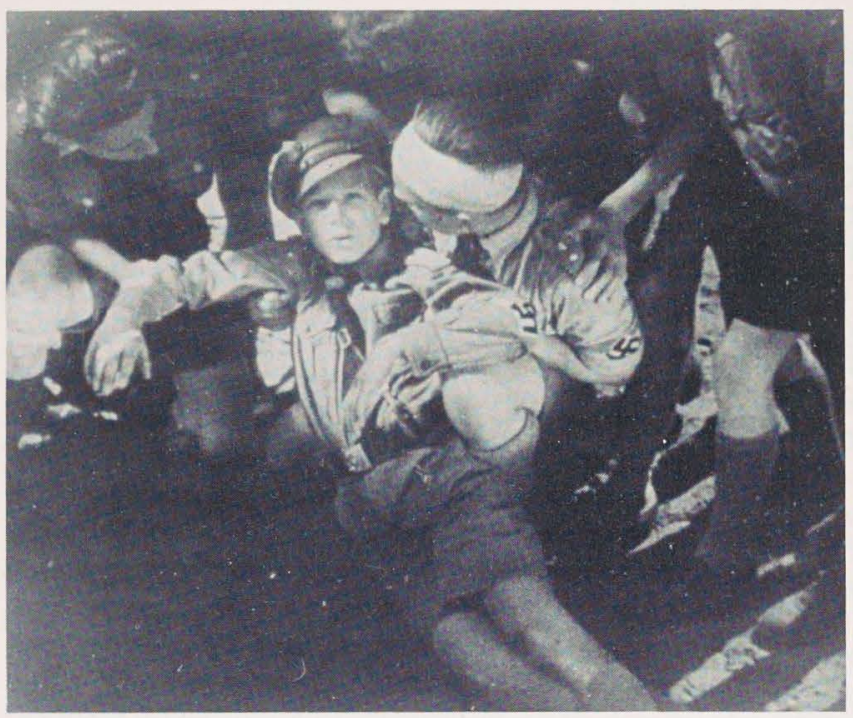

Figure 5 Heini dying in the arms of his Nazi comrades.

\section{"Through death to a millennium"}

Our flag billows [flattert] before us!

We advance [ziehn] into the future man for man! We march for Hitler through night and pain [Not] With the flag of youth for freedom and bread! Our flag billows before us!

Our flag is the new epoch [Zeit]!

And the flag loads us into eternity [Ewigkeit]!

Yes, the flag is more than death!

Or, in one phrase, we may summarize the time perspective of the film as "through death to a millennium." This time perspective is interesting in several ways. It is, of course, the characteristic time perspective of the great fanatical revivals and nativistic cults, from early Christianity through Mohammedanism and Marxism to the Ghost Dance of the American Indians and the Vaihala Madness of New Guinea. The same basic view of life, "through the unpleasant to the pleasant," recurs again and again, but the specific pictures which are drawn of the unpleasantness and of the later reward vary from one culture to another. The unpleasantness may be death or political chaos or persecution or striving effort; and the final reward may be either in this world or in the next. It may be a sensuous reward, a military victory, or an ivory tower. The prognosis for any cult will depend on how the two successive phases of this time perspective are conceived and on the likelihood of events fulfilling expectations.

In this film there are two such cycles, in which Heini goes through death: first, his incomplete death when his mother turns on the gas and second, his final death at the hands of the Communists. What sorts of death were these and to what sort of millennium did they lead? 
The two deaths have a number of features in common: 1 Each follows some conspicuous achievement on Heini's part. The gas death occurs after he has rescued the Nazi boys and enabled them to blow up the Communists' dynamite; the final death follows his successful distribution of leaflets in the Communist district after the Communists thought they were all destroyed.

2 There is a woman involved in both deaths. The gas death is the final episode in Heini's relation to his mother; and the final death follows Ulla's kiss.

3 Each death is represented on the screen by a sort of billowing or waving motion. In the case of the gas death, we see the fumes fill the screen and move like heaving waves. In the final death, it is the Nazi flag itself which fills the frame and billows before us. ${ }^{6}$

4 Each death is accompanied by a change in illumination. The gas death occurs in a darkened room, and after it the fumes fade away to disclose Heini in a brightly lighted hospital ward. In the final death Heini distributed his leaflets and was encircled by the Communists in darkened streets; he takes refuge in the dark tent of the deserted fair; he is stabbed in the dark. We then see his legs faltering as he comes out of the tent in a half light and finally, when the Nazis find him dying, we see full daylight.

Each death accompanies a change in Heini's status. By the gas death he shifts from his family home to a hospital, a sort of neutral ground halfway toward Nazism. By his final death he moves from the world of the living to the world of reincarnated heroes.

In each death Heini's last words refer to the future. In the gas death, his mother says, "Heini, settle your quarrel with him [Stoppel] or else everything is lost [sonst ist alles aus]." And Heini replies, "But Mother, now it is just beginning [Jetzt faengt es doch erst an]." In the final death, Heini's last words are:

Our flag billows before us

It leads.

[See Figure 5.]

Each death is rather amply predicted. The gas death is predicted by the mother at the beginning of the film when the father comes home hurt. She says, "You'll bring us all into misfortune [Ung/ueck] again." Later, while Heini is coming home from the hike, we are shown a shot of the mother lighting the gas, and finally, just before the event, she says, "Everything is lost" (quoted above). The final death is predicted by the district leader's anxiety, by Stoppel's and Gerda's warnings, and by the heavily weighted scene in which Wilde picks up the knife. Each death is tragic in the classical sense of being the final outcome of an inevitable sequence of events.
These features which are common to the two deaths give us together a rounded picture of Nazi time perspective. To get this picture, it is important not to think of these features separately as they are enumerated above but to combine them into a hazy sense of the total Wel-

tanschauung. The achievement, the woman, the billowing, the change of light, the change of status, and the destiny idea together make up a state of mind which can only very inadequately be expressed in words - an ongoing state through some sort of orgasmic upheaval to a final millennium.

The final term in the Nazi time perspective is of special interest. The beginning of the cycle, through suffering and effort to individual death, is comparatively common in fanatical cults, but the final goal toward which the Nazi nominally strives is a rather unusual one. It appears to be a sort of multiple reincarnation in this world. Heini's corpse is replaced on the screen, first by the flag, then by columns of marching Nazis, and in this final shot some trick photography has been used so that while we see the innumerable marching figures moving obliquely away from us, we also see, faintly superimposed on them and much larger, the waists and thighs of uniformed Nazi figures striding toward us. Even after the passage through death, there is promise of future turmoil, sexual and aggressive.

A similar promise of multiple reincarnation is still more explicit in another Nazi film, Fuer Uns (1937). This is a documentary account of a Nazi party ceremony in which we see the dedication of sixteen concrete blocks to the memory of the sixteen martyrs of early Nazism. Each block has on it the name of a hero (Hans Schlageter, Horst Wessel, etc.) and the words "On call" (Zum Appel). Each block supports a great urn in which flames billow. As a wreath is laid at the foot of each block, the name of the hero is called, and a thousand men somewhere in the stadium answer "HERE." The procession goes on to the next hero, and again the answer comes back from another section of the stadium.

Before leaving the subject of Heini's deaths, it is necessary to ask why there should be two of them. In this, the film transgresses the ordinary canons of tragedy, but the reasons for this transgression lie in the peculiar social structure which Nazism seeks to set up. In place of the more common type of social system based on the family, Nazism substitutes a system based on what anthropologists call "age grades."7 The youth of the nation is to be divided into blocks from small boys (Pfimpfen), from 6 to 10 years old, up to the fighting units of S.A. The step from each grade to the next is accompanied by an arduous initiation ceremony. ${ }^{8}$

Initiation ceremonies, and other rites which symbolize the passage from one social status to another, usually include a symbolic statement of the candidate's death as a member of his former group followed by a symbolic statement of his aggregation into the new group. Thus, in giving Heini two deaths, the propagandist has epit- 
omized a whole social system and a time perspective which envisages repeated symbolic deaths. Heini's final death implies that the long series of symbolic deaths representing promotions from one age grade to another will reach its climax in a real death and multiple reincarnation. His first death by gas tells us that the entry into the age grade system is itself a passage rite, differing only from other passage rites and initiations in that Heini's mother, instead of mourning the loss of her boy when he leaves the family, is herself killed.

In killing the mother in this way, the film does more violence to the conventional folk philosophies than is immediately apparent. It is not only that the film kills off a member of the group which Heini is leaving but, specifically, the mother is the predictor of tragedy, the representative of fate. This theme is not very striking in this particular film. We hear the mother at the beginning say to the father, "You will bring misfortune on us again," and later she dies, but this combination is not shocking to the average spectator. That this combination may be significant, however, is demonstrated by another Nazi propaganda film, Faehrmann Maria (Ferryman Maria, 1936), an allegory specifically concerned with death. In this film, the old male ferryman (a figure who reminds one of Charon) dies in the arms of an austere male figure representing Death. The place of the old ferryman is taken by a beautiful ferrywoman, Maria. She cheats Death of a young male victim and deceives Death into following her across the swamps in search of this victim whom she loves. Death's foot slips, he sinks into the swamp, and the last we see of him is his hands pleading for rescue. Maria then tells her lover, "The way is open to the homeland [Heimat],"9 and they go together hand in hand across the river and over the hill.

This second film does very great violence to occidental notions about Death and shows us that the death of the mother in Hitlerjunge Quex - the killing of the personification of fate - is possibly significant. German thought, both pre- and pust-i litier, is very much preoccupied with ideas of destiny, interwoven with ideas of duty, racial superiority, and providence, and it is natural to compare the destiny notions in Hitlerjunge Quex with those in Faehrmann Maria. The second film leads us naturally to look in Hitlerjunge Quex for a second Destiny or Providence figure who should be a young female, replacing the dead mother.

This role is filled by Ulla. Twice Ulla works like Fate or Providence behind the scenes, to reverse the course of the plot. First, when Heini is caught spying on the Nazi hike, Fritz is angry and sends him away, but after he is gone we hear Ulla's voice saying, "He might have been one of us." The audience is left with the impression that Nazism is inaccessible, and this impression is reinforced by the distant views of the Nazi camp at which Heini gazes the next morning. But on the following day Heini has no difficulty in approaching Fritz, who at once invites him to dinner. Later in the film we see another reversal of the same sort when Heini telephones to warn the Nazis about the dynamite and Ulla hangs up the phone under Fritz's orders. Heini is left unable to make contact with anybody, but the explosion occurs. Nothing is said to explain either of these reversals, and only one explanation is possible: Ulla, on both occasions, worked like Providence behind the scenes. Thus into the whole notion of death and the time perspectives there has been infused a sense that Death and Providence should be the object of the sorts of attitudes which the Nazis would direct toward the desirable female (see Analysis IV). Such a reading of the film will account at once for the use of orgasmic billowing symbols to represent death.

In concluding this discussion of the time perspectives expressed in this film, it is appropriate to consider how this film differs from others. Insofar as a time perspective involves an expectation of change in the course of events, the perspective itself and its implications for character may alter as time goes on. The expected climax may occur, in which case the former time perspective is satisfied and a new one must be constructed. Alternatively, the climax may not occur and some modification must then be introduced into the time perspective to accentuate or relieve the frustration.

Almost simultaneously with the production of Hitlerjunge Quex, other films were produced with the same basic time perspective, "through death or chaos to a milIennium," but the chaotic phase is not always symbolized by personal death. In Bluten des Deutschland, this phase is directly equated with the political chaos of the twenties, while in Hans Westmar, a film based on the story of Horst Wessel, individual death and the political chaos are simultaneously invoked. Thus in these films it was possible for the filmmaker to present the notion that the worst of the chaos was already over. The possibility of chaos still remains as a threat in case the nation should not dutifully follow its Nazi destiny, but the time perspective is not, as in Hitlerjunge Quex, that of a man faced with the whole uphill climb and only the distant promise of the summit. It is rather that of a man already more than halfway up the hill and able to look back on what he has accomplished.

When, however, we look at a much later film, Ohm Krueger (released in April 1941), we find an entirely different time perspective. This film deals with the story of the Boer War, and the Boers, fighting England, are clearly the model that is held up before the German audience. The film starts after the Boer War is over. We see Krueger as an old man suffering from psychological blindness in a hospital in Switzerland. He is looked after by a young nurse to whom he narrates the story of the war. The film then cuts back to South Africa, and we see the Great Trek followed by disreputable intrigues attributed to Rhodes, Jameson, Chamberlain, Queen Victoria, and others. The war begins with prodigious victories for the Boers and 
ends with utter defeat. We see the graves of the Boers, and then the film returns to Krueger, in Switzerland, who predicts that all this suffering will be avenged by some greater nation.

The time perspective implicit in this film seems to be the precise opposite of that of the films of the early thirties. Instead of "through death to a millennium" this later film offers us "through preliminary victories to ultimate defeat"- a time perspective which probably results from the resemblance between World Wars I and II. We may note, however, that Hitlerjunge Quex and Ohm Krueger are alike in assuming an enormous pendulum swing in the tide of human events. Ohm Krueger may bode better than Quex for a United Nations victory, but the problem which will confront us after the war is that of steadying the pendulum —of inducing in Germany an expectation not of climax but rather of steady progress.

\section{Analysis II: Political Groups and Backgrounds}

The first analysis of the film dealt with the climax structure of the film as a whole and related this to the time perspectives of Nazism. In contrast to this, the present analysis is static. The element of time is here deliberately overlooked, and instead this second analysis will consider how Nazism and Communism are characterized in the film.

The film actually deals with three types of social grouping - Communism, Nazism, and the family-but of these the family is a sort of no man's land over which the battle for Heini's future is fought. In this battle Heini's relationship to his parents evolves and changes, the emphasis shifting according to the propagandist's technical needs. Analysis of the family, therefore, cannot be handled in static terms, and is reserved for a later section. The present analysis is confined to Communism and Nazism, which are consistently characterized throughout the film.

The very first shot of the film lays the base for the characterization of Communism. It is a close-up shot of a single apple which fills the screen-a double symbol of food and sexuality. From this the camera trucks back to include the whole heap of apples in the vendor's store, and we see two boys, whom we later discover to be Communists, debating whether to steal the apples. They are hungry and without money, and suddenly one of them snatches an apple and runs. The vendor grabs the boy and begins to box his ears.

A second characterization of Communism follows in the same sequence. Wilde, the sinister Communist agitator, makes a speech beginning, "Workers [Proleten], hear me. It is not this boy alone who has been boxed on the ears. I tell you that all you who are here have had your ears boxed."
Thus in a single sequence Communists are characterized as unstoical in the face of temptations of the mouth and as making political capital out of purely human woes. ${ }^{10}$ In doing this the propagandist has resorted to two sorts of biblical reference; he has invoked the apple and has put Christlike paraphrasing into Wilde's mouth.

Stoppel's behavior when he accompanies Heini's father to his home and helps the mother to dress the father's wound further illustrates this use of human woes. He takes advantage of the situation to contact Heini for the Communist Youth International, and later, at the fair, when Heini has lost his money in the lottery, he again exploits this woe, comforting Heini by inviting him on the Communist hike.

On the hike, we see the contrast between the ragged, disorderly Communists and the neat, disciplined Nazis, and we are told almost in so many words that this contrast is a part of the emotional dynamics upon which Nazism rests. A platoon of Nazi girls in uniform is standing on the station when a disorderly mob of Communists comes by. At the head of the Nazi girls is Ulla (though the audience does not as yet know that this girl will play a special part in the story). Just before the arrival of the Communists, Ulla's head droops forward in a very unmilitary posture, but when she sees the Communists, she suddenly raises it and holds herself properly erect. Her gesture implies that the emotional value of Nazism is not simple and positive; it is also negative: it is a pride in not being the sort of people that they accuse their enemies of being (see Figure 4).

Immediately after this incident, the film begins to develop the themes which were first suggested by the apple. We see the Communist boy who stole the apple take chewed food from his mouth and fling it in the face of one of the Nazi boys, ${ }^{11}$ and in later stages of the film we repeatedly see the Communists indulging in grass eating, throwing their food, passing a half-eaten apple from one to another, smoking cigarettes (the Nazis apparently do not smoke), and drinking schnapps (the Nazis drink only beer).

The response of the Nazis to the insult of the thrown food is interesting. For a fraction of a second we see them break their ranks and prepare to indulge in a completely disorderly brawl. The district leader barks a command, and they return to attention. But in this fraction of a second the psychological base for the whole propaganda system is exposed. The Nazi assumption is that, but for the barked command and their veneer of discipline, they themselves would be the same sort of disorderly rabble they represent the Communists as being. ${ }^{12}$

This assumption reappears when Heini is living in the Nazi clubhouse. Heini is referred to as "Quex" at a meal, and when he shows resentment at this nickname, a disorderly brawl breaks out, involving all the Nazi boys. Some of them fight in one cluster and some in another in a completely disorganized manner, until a barked com- 


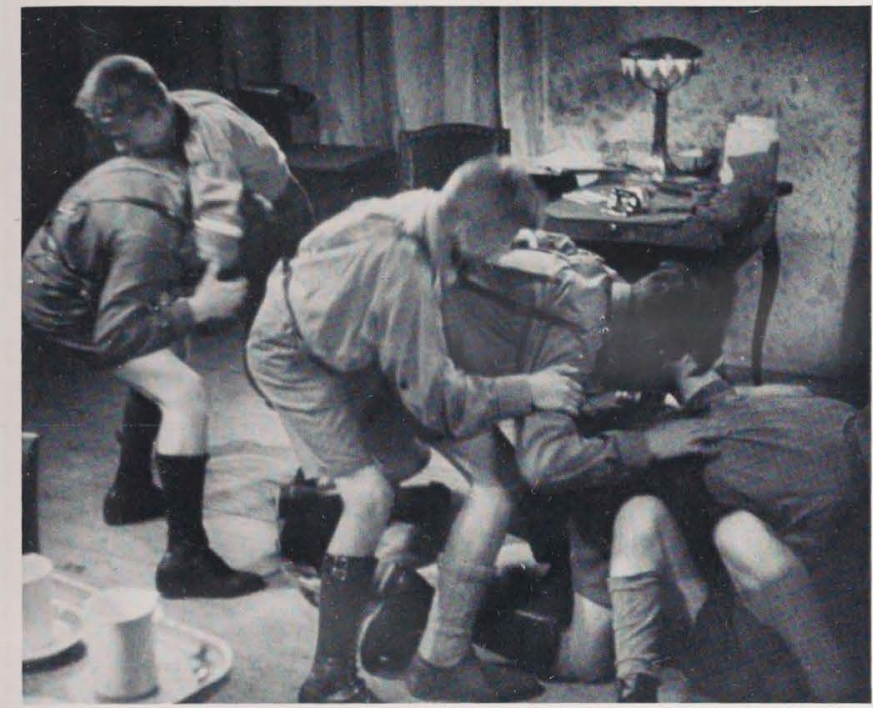

Figure 6 Hitler Youth brawling in their clubhouse.

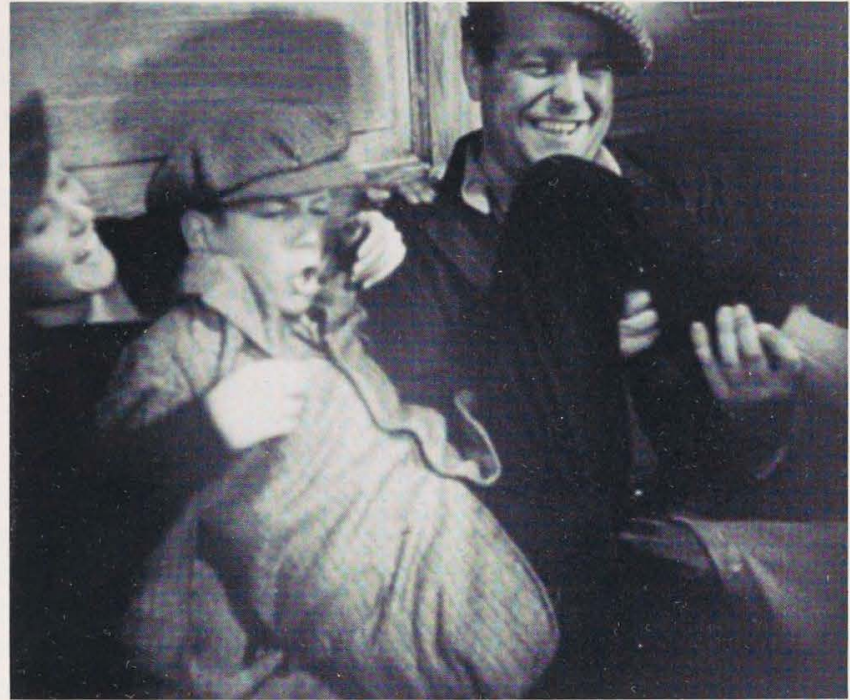

Figure 7 Heini is pulled down by Gerda and exclaims, "You are a girl!" mand from the district leader freezes them into guilty immobility. (Figure 6.)

Here the disorderly characteristics which the film attributes to the Communists are another example of the Nazis' habit of attributing their own real or potential vices to their enemies, and we shall see that the whole characterization of Communism in this film is, in a sense, a self-portrait of Nazism. It represents what the Nazis think that they themselves would be like without their discipline or, psychologically speaking, what they are like under the veneer of that discipline.

The sexual suggestion which was implicit in the apple is also developed on the hike. When Heini enters the compartment on the train, Gerda, the Communist girl, seizes him around the neck and pulls him down onto her lap. His back is toward her, but she forces his face around until she is able to plant a kiss on his lips. Gerda is wearing a boy's cap, and as Heini stands horrified, she pulls the cap off her head. Heini, still more horrified, says, "You are a girl," and she replies, "You notice everything." (Figure 7.)

This kiss might appear sufficient to smear the Communists with the combined reproach of sexuality and mouthiness, but the propagandist was apparently not satisfied and he borrows a Freudian recipe to drive the point home. We see Stoppel push a peeled banana into Gerda's mouth with the palm of his hand, and this moment is chosen for the others to start to sing the "Internationale." (Figure 8.)

Later, in the camp, we see another characterization of the Communists, in which a Freudian recipe is once again borrowed. They play a buttocks-slapping game (Schinkenkloppen). The boy who stole the apple is held bent over so that he cannot see who slaps him. Gerda supplies the slap and then self-consciously looks the other way. The boy guesses correctly that she is the guilty one, and she in turn is grabbed by the crowd and held while the boy spits on his hands preparatory to taking his revenge. Heini at this point turns away in disgust. ${ }^{13}$

These characteristics are attributed to the Communists whenever they appear on the screen. Almost always they have food in their hands, and when the filmmaker wants to show us that Grundler's character is degenerating under Gerda's influence, he does so by having Grundler smoke a cigarette in a lackadaisical manner. While he smokes he sings a snatch of a cheap popular song, and when he sees Heini's photograph of Ulla, he assumes that she is a sexual object (Flamme).

In contrast to the Communists, the Nazis are almost colorless. We see their parade-ground smartness, we see them dashing into the sea to bathe, but these behaviors are the negative of the excesses which are attributed to Communism, and throughout one is left with the feeling that Nazi life is empty. On three occasions we see them eat-on the hike, in the Nazi clubroom, and at the home of Fritz and Ulla-but except on the hike, where the Nazi eating is contrasted with the throwing of food by the Communists, their eating habits are not specifically used to characterize them. In the Nazi clubroom the meal is merely the setting in which Heini's nickname is given him, and at the home of Fritz and Ulla, it is the whole upper-middle-class background which is significant, rather than the eating.

On the sexual side, the film shows us something of the courtship behavior and attitudes which Nazism held up as an ideal in 1933. These, however, can be analyzed only in connection with their whole handling of the family, 


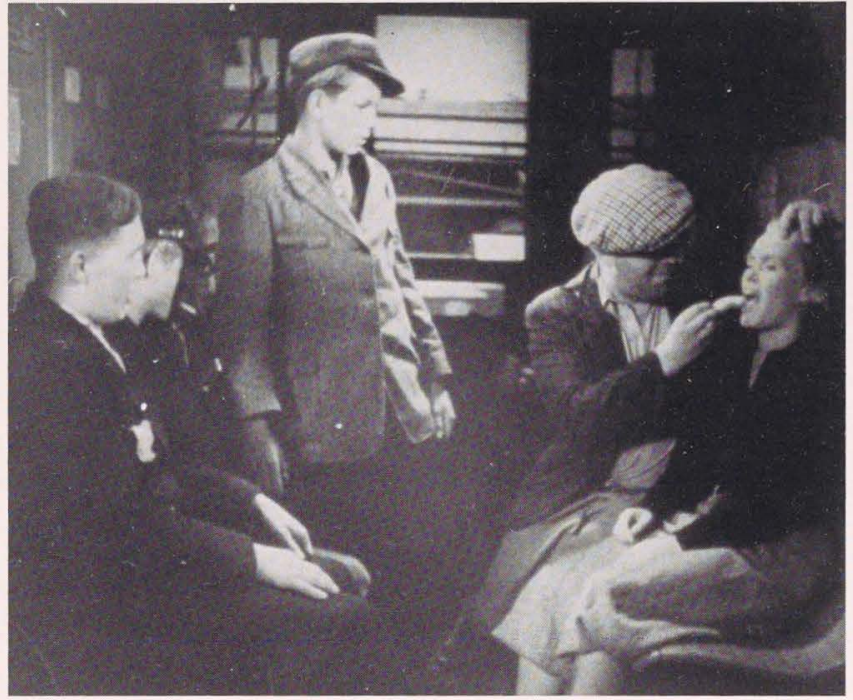

Figure 8 Comrade Stoppel stuffs a banana in Gerda's mouth while the others sing the "Internationale.'

and we shall therefore confine ourselves here to the question of the psychological nature of the sexual contrast. We have noted that the contrast in terms of orderliness is based on the Nazi habit of referring their own disapproved weaknesses to their enemies, and two types of evidence are available to show that the same is true of the sexual conquest.

The first evidence is of the same general type as that which we used in the case of orderliness-disorderliness. The Nazis used the premise that they themselves would be disorderly but for their discipline as an argument in favor of their whole system; and in the same way they employ the argument that they would be sexually depraved. The story of Grundler's fall is propagandic in this sense.

The story begins on the morning after the hike when he and the other Nazis are distributing leaflets. Gerda, under Stoppel's orders, contacts Grundler, asking him for a leaflet and then for another and another till he gives her all he has. Then she throws all the leaflets into the river and starts a flirtation with Grundler by asking him for a cigarette. A few minutes later she says she wants "Turkish Delight." He asks where they can get this, and she says, "At the fair." We then see Grundler falling in step with Gerda on the way to the fair. Later we see them dizzily riding the merry-go-round, and the camera stoops to pay special attention to the swinging legs of the boy and girl. From this point on, Grundler's uniform becomes more and more slovenly, and finally, under Gerda's influence, he enters into a plot to destroy the entire supply of Nazi leaflets. He brings the leaflets on a barrow to a rendezvous with Gerda, and together they throw all the bundles of leaflets into the flowing river.
The inclusion of Grundler in the film can partly be explained as a bid for "truthfulness," an attempt to make the audience say to themselves, "Yes, the film is not an idealized picture of Nazism because, after all, they do show a bad Nazi," and, of course, the propagandist can safely show this bad Nazi because the showing is accompanied by disapproval of Grundler's weakness. Actually, however, they have shown a Nazi who is not only bad but deteriorating, and thus, consciously or unconsciously, they have again preached that Nazism has a double quality. On one side, Nazism may have the fine overpurity of comradeship (Kamaradschaft), but this purity carries with it, on the other, the tendency to deteriorate in a particular direction.

This is by no means the double nature attributed to many by the more familiar Christian sects. Christianity has classified the forces which work to mold man's behavior in many ways, and no doubt the Nazi tendency toward dualism owes something to the dualistic thinking in other religions, but the actual content of the dualism is fundamentally different. Christianity sees man in various dualistic frames; it sees him as divided between mind and spirit, reason and emotion, soul and body, conscience and temptation, and so on. But even the most pessimistic of Christian beliefs, those which assign maximum strength to the taint of Original Sin, have never omitted from man's nature some traces of spontaneous goodness. The Christian dualisms have always assumed good and bad elements within the individual man; they may have insisted that the good side needed external help from church or minister, but they have never seen man as a mechanical creature who should be passive vis-à-vis an external disciplinary authority. In the Nazi view-and the same is true of the handling of temptation and depravity in many pre-Nazi German films-man's nature will respond almost mechanically to bright lights, the whirl of circuses, and city life. He will inevitably be sucked down into a swamp. ${ }^{14}$

The second type of evidence, which shows that, in attributing a certain sort of sexuality to the Communists, the Nazis are merely describing the worst side of their own nature, is indirect. If the Communists were represented as merely different from Nazis, the filmmaker could claim that he was simply giving an objective picture. But these "Communists" are not simply different from Nazis; they are a systematic opposite of the Nazi ideal. This relationship is, of course, what we should expect if the attributes of "Communism" are psychologically rooted in the Nazi character, and while it is conceivable that this relatedness might be due to coincidence, such a coincidence would be unlikely.

The clearest indication that "Communism" as here depicted is only the obverse of Nazism comes from the makeup of the two girls, Gerda and UIla. Gerda, the Communist, is more heavily female in her head and torso. Her hair strays loose; she continually expresses her sexual desires and frustrations with gestures of the lips; and 
her breasts are evident through her sluttish blouse. But in contrast to this femaleness in her head and torso, her legs are usually clothed in slacks. Ulla, on the other hand, is the precise reverse of this. She wears a skirt, but from the waist up she is progressively more boyish. Instead of a blouse she wears a Nazi shirt open at the collar and loosely held with a tie. She has straight blond hair, bobbed and severely parted. She wears a beret.

This contrast may be summarized by saying that if Gerda's head and torso were set on Ulla's legs, a complete female figure would result; whereas Ulla's torso on Gerda's legs would give us a complete boy. They are not just two people, different one from the other; they are a pair of people, each systematically related to the other. Gerda is a postadolescent female with male legs, and Ulla is an adolescent or preadolescent boy with female legs. ${ }^{15}$ The same type of systematic contrast occurs also between Heini's father and the district leader, and again between Heini and Grundler, and these two contrasts will be examined at a later stage of the analysis. It is evident, however, that the likelihood of these three systematic contrasts all being due to coincidence is very small, and we may take their systematic nature as evidence for the fact that the depiction of the Communists is a function of the Nazi character.

Last, we cannot leave the consideration of the contrast between Nazism and Communism without examining the backgrounds in which these two political groups are set. The filmmakers went out of their way to blacken Communism by photographing the Communist scenes in poor light. Even Heini's home is murky and sinister; the fair so much frequented by Communists is poorly lit; and the room in which the Communists meet is clouded with tobacco smoke. In contrast to this, the home of Fritz and Ulla and the Nazi clubroom are brightly lit, and on the hike we see Heini progress from the murky Communist camp through darkness to the scene in which the Nazis celebrate the solstice, where their beacon fire gives bright contrasts of illumination. When he is dismissed as a spy, Heini retires into the darkness, but next morning he is shown a brilliant scene of the Nazis on the beach in the morning sunlight.

In general, these shifts between light and dark are satisfactorily woven into the plot, but at the very end of the film, one shift from darkness to light seems arbitrary. We see Heini encircled in the darkened street and he is killed in the dark, but when the Nazis come to pose beside his dying body, it is broad daylight.

In addition to darkness, the background of Communism is characterized by various kinds of spinning objects, the merry-go-round, the lottery wheel, and spinning targets in the shooting booth. It appears that the Nazis conception of the sort of sexuality which they attributed to Communists is closely linked with feelings of dizziness. Man, the mechanical puppet, is endlessly liable to be swept off his feet into some sort of whirlpool. ${ }^{16}$
The relationship between the dizzy background and sex is especially clear in the scene in which Stoppel invites Heini to the Communist hike. Behind them while they talk is the whirling merry-go-round, and their conversation is interrupted not only by the mechanical music but also by Gerda's voice. Gerda is riding one of the horses, and whenever she passes Stoppel she calls out to him. Finally, at the end of the conversation, Stoppel jumps on the moving merry-go-round, like a frog jumping into his pond.

In addition to the use of these dizziness symbols, Communism is twice characterized by the river. This occurs at the beginning and end of the story of Grundler's fall. First we see Gerda throw Grundler's leaflets over her shoulders into the river, and finally we see Grundler and Gerda together throwing the main supply of leaflets in bundles into the water. Probably the appropriateness of this symbol derives from some notion that Communism sweeps all good things away.

German cameramen are exceedingly fond of photographing waves and ripples, and these symbols are usually used to denote some pleasant or desirable emotional state. In the first scene, when Gerda throws the leaflets over her shoulder, we see the river behind her, smooth and shining in the sunlight. Here the river probably reinforces the idea of Gerda's attraction. In the final scene, we see the river at night with the lights of the city reflected in it so that the river becomes a symbol of the seductive, bright lights. On neither occasion do we see waves, which are reserved instead for association with Nazism. We see the sea (or possibly a lake) when the Nazis run into it to bathe, and the Nazi flag, whenever it appears on the screen, billows with a wave motion, and the gas fumes billow like a flag or like water. Thus Nazism is associated with the movement of waves.

There is clearly a rather close relationship between the hypnotic fascination that comes from staring at waves and that which comes from looking at spinning objects, and this relationship is probably another facet of the relationship which we have already noted between Nazism and the Nazi characterization of Communism. There is, however, an important difference between waves and spinning objects. Waves contain an illusion of progress, of forward movement, but spinning objects evidently get nowhere. It is possible that the waves used to characterize Nazism are related to the endless marching which has such great fascination for Nazis and which appears in almost every Nazi film. Only in its endlessness does this marching resemble the spinning of the symbols associated with Communism.

These two introductory analyses, the first of Nazi time perspectives and the second of characterization of Nazism and Communism, enable us now to go on to examine how the filmmakers handled the mixed emotions present in the German family and how they have marshalled these emotions to make them support Nazism. 


\section{Analysis III: The Family of Origin}

From a propagandist's point of view, and also, perhaps, from that of an artist, the contrast discussed above, between Nazism and Communism, is the weakest part of this film. The contrast is stated openly and didactically so that the audience is fully conscious that a contrast has been presented and, being fully conscious, is therefore free either to accept or to refuse it. Indeed, we may suppose that if the only propagandic message in this film were its idealization of Nazism and its caricaturing of Communism, its effect on a mixed audience would be merely to reinforce Nazism in those who were already converted, while those who preferred Communism would be able to repudiate the caricature so that the film would only anger them and make them more Communistic than before. The contrast by itself would not make converts; it would only increase antagonism.

The great strength of the film lies elsewhere, however. Heini's preference for Nazism dates clearly from his seeing the contrast, but from then on his progress toward Nazism is tied up with his relations with his father and mother in a way that endows Nazism with a psychological force much greater than it would otherwise have. The family scene as it is presented to us is one of extreme intensity, from the first moment that Heini appears in the doorway and sees his father in a temper tantrum, demanding money from his mother. And later, when we see a pleasant, warm relationship between Heini and his father-when the father gives him the house key - the emotions, though of a different kind, are no less intense. In general, the propagandist evokes all the intensity of emotion that lies latent in the German boy's relationship to his family, and as the film progresses, these emotions are rearranged and harnessed to give dynamic force and fanatical violence to Heini's Nazism.

The present analysis from the kinship angle is an attempt to show how this is done and to outline the implications for the Nazi character that follow if we suppose that the fanatical intensity of this cult is largely derived from certain themes of pre-Nazi German family life. ${ }^{17}$

In a strict, narrow sense (excluding possible spouses and parent substitutes), Heini's family consists of himself, his father, and his mother, and of these the first to appear on the screen is the father. We see him in the opening sequence of the film as an unknown man in the crowd at a food riot. He is a big, heavy man, poorly dressed, clumsy and violent, but with unexpected warmth and gentleness. The first characterization of him is as a kind person. We see him speak against the crowd that wants to imprison the two boys who stole apples when driven by hunger. The father pushes his way forward through the crowd, and he speaks simply, as a human being without party alignment. He sees the incident not as a political allegory but simply as a peccadillo. He points out that you don't put a boy in prison for one apple - "especially when the boy has not even bitten it." At this stage, the propagandist is careful not to associate the father with Communism and the father is sympathetically treated. A riot starts, however, fomented by Wilde, the Communist agitator, who treats the incident of the apple as politcal material:

"Workers, listen to me. Here not only this boy has had his ears boxed, but also you who are here have been boxed on the ears." In the riot the shopkeeper upsets his own apples, and then there is a shout, "Police!" As the crowd scatters, the father stumbles over the edge of the sidewalk and strikes his head against the wall. He stands leaning against the wall and groaning on the porch of his own home. He is helped up the stairs by Stoppel, an organizer of the Communist Youth.

The following sequence includes the father, the mother, and Stoppel, and it is important to watch how Stoppel becomes included in the set of relationships which constitute the family. The relationship between father and mother is immediately and sharply defined. The mother is dominated by the father, and yet he is as dependent on her as a child. When he enters with his injury, she cries out in horror. This is the only evidence of love for him that she shows, and as the sequence develops we realize that his injury is not serious. The father groans when the wound is washed, but this is plainly due to his lack of stoicism. Stoppel joins the mother in ministering to the father.

The mother, after washing the cut, solicitously offers the father a drink of water, but he with an oath demands beer. The mother says, "But that costs money!" He then asks where Heini is so that he can send him to get two bottles, but the mother replies that Heini is still at work.

This sequence has set up the following definitions of the personalities and their relations to each other: the father is unstoical and dependent upon the mother; the mother is a drudge, solicitous for the father, and Stoppel is associated with the mother in caring for the father.

At this point the sequence is cut to let us see Heini at work in a printing shop, where he receives a tip of one mark from a customer. He and the printer regard this as a great windfall, and the printer makes a tentative effort to take the mark from him (lest the mark should appear to the audience to have been too easily earned). Heini successfully resists this and goes home.

The camera now returns to the father, mother, and Stoppel. The father asks for money so that he can buy beer-"Mother, won't you give me a few pennies?"--thus underlining his dependence on her; and when she professes to have no money, he becomes more and more violent and domineering. He starts searching in all the containers in the house, first looking in the coffee pot and then throwing it down, pulling out drawers and scattering the clothes, then scattering the photographs out of the family album, and so on. Both Stoppel and the mother try to quiet him. Stoppel says, "Man, don't make a circus (Zirkus $)^{18}$ here." But the father continues to advance, angry and domineering, toward the mother, who slowly retreats backward, facing him (see Figures 2, 3). 
At this point, Heini appears in the doorway. He arrives home at the precise moment of the height of the father's tantrum, and for a moment he hesitates in horror, so that, when the camera returns to the father and mother, we see their relationship through the eyes of their son. Almost immediately Heini goes over to the mother and secretly slips the mark into her hand. She raises her hand and opens it, and the father seizes the mark. His temper tantrum suddenly subsides; he spits on the mark and says, "There, you see, one has to show one's teeth in dealing with women."

This very dramatic sequence burns into the audience the whole stereotyped family picture from which Nazism draws its emotional power. Heini is for a moment paralyzed with horror at the conflict in which his parents are engaged, but this hesitation is resolved when he goes and gives his mother the mark. In contrast to the father, he, Heini, is the mother's slave, and she, at least in this instance, is dependent on him. He is the rescuing hero in his own eyes and in the eyes of the audience.

The emotions and attitudes of the rescuing hero are precisely those which the propagandist would like his audience to apply to Nazism or to Germany. But this incident has a double significance. At a superficial level we can see Heini as the hero, but while he is being heroic, he is also at a slightly deeper level joining his mother in passive appeasement of the father. ${ }^{19}$ And this passivity also can be orchestrated into the emotions which Heini will give to the Party. In the end, the propagandist wants the audience to feel that utter passivity to the demands of the Party is a form of rescuing heroism, and this incident presents the ideal model for such a combination of emotions. Heini's passivity toward his father is glorified by being at the same time a rescuing of the mother, and this glorified passivity has now only to be shifted to the Party and/or the nation.

The film does not go into the question of the relationship between Party and nation, and it seems that to have attempted this would have landed the propagandist in difficulties. Starting from three symbolic units, the son, the father, and the mother, he would have had to end up with two, the party and the nation, and the basic instability between these two would eventually be disclosed. If the nation were equated with the mother, then the Party would have to combine the father's authority with Heini's heroism, and would therefore become a recipient of ambivalent emotions. We should see all too clearly that Party and nation could only exist side by side if perpetually fed on scapegoats and enemies, which would provide an object for the negative parts of this ambivalence. Passivity can be glorified only by emergency, and there must be imagined danger from which somebody can rescue somebody else.

We have now seen son and mother united in mutual love against the father, and Stoppel has received a sympathetic characterization through his association with the mother in aiding and placating the father. Now Stoppel takes advantage of the occasion to contact Heini for the Communist Youth International. He first praises Heini to the father and then asks if Heini is "organized." The father tells him to ask the boy himself. In a later scene the father signs Heini into the Communist Youth willy-nilly and brushes aside the mother's suggestion that Heini ought to be asked, but at this stage of the film Communism is still being given a favorable build-up. We are not allowed to identify the father as an active Communist but only, perhaps, as a mild Social Democrat.

Stoppel has a few words with Heini. He asks him if he is "organized," but Heini apparently does not even know what the word means. Stoppel says that of course Heini belongs naturally in the Communist Youth International"or do you want to be a Nazi?" The father scoffs at this idea, saying, "What! — my boy a Nazi—l'd sooner kill him." The father then goes off to get his beer, and after taking leave of Heini and saying that they will talk it over later, Stoppel, too, goes away.

This leaves Heini still the rescuing hero with his loving, drudging, and weeping mother. She sighs, "That is no life - cannot bear it (das halt ich nicht mehr aus)." Heini continues in a comforting role for a moment, telling her not to be always so sad. But she goes and opens the window. This act lets in the mechanical music of the fair, which, as we have seen, is associated throughout the film with the orgies and degeneracy of Communism. It is the mother who lets in this music, and Stoppel the Communist has so far been associated with her rather than with the father. And now it is the music of the fair which leads Heini to desert his heroic role. He gazes for a moment out of the open window, and then he remembers a wonderful knife he saw at the fair in a lottery in one of the sideshows. He turns back to his mother and starts to describe the knife, listing its many blades - "and it has a saw, too." She says, as she said before about the father's beer, that it must cost money, but Heini tells her it is in a lottery and can be had for a penny. He begs her for the penny just as his father begged her for money (see Figure 3).

In spite of the fact that Heini has now shifted from a rescuing to a dependent role he is still a hero in her eyes, and very slowly she smiles on him-a slow, almost seductive, Mona Lisa smile. Thoughtfully she rises to her feet and moves across the room. As she moves, the music of the fair, which hitherto has been almost formless, becomes rhythmical, and she moves in step with it. She goes and gets money from a hiding place inside the coffee grinder.

Thus she confers on her son the favor she had refused the angry father, but we are shown very clearly that Heini is no longer really a hero. As she crosses the room, he watches her appraisingly-judging the success of his plea for money. He smiles secretly when she starts to shake the coffee grinder and rapidly removes the smile from his face the moment she turns to give him the money. Then he dashes out to get the coveted knife. 
In thus going out to get the knife with his mother's money, he is performing an act closely comparable with the father's going out to get beer, and indeed both the knife and the beer are natural symbols for a certain sort of virility. Through this crack in the knight's armor Communism enters. The pennies are, of course, immediately lost in the lottery, and the "of course" element in this loss is underlined by the casual impersonal quality of the lottery scene. The lottery is a swindle, in which a large number of prizes are exhibited but the competitors do not know which prize is being put up at any given turn of the wheel. When the wheel is spun and the winning number announced, the prize is not the knife but a cheap vase $e^{20}$ of artificial flowers, and it is won by a silly woman. Heini shyly asks how much the knife would cost to buy, and the man says, "8 marks"- the knife is inaccessible.

But Stoppel, the Communist, is there in the background. For a moment Stoppel and Heini pause to listen to a ballad singer (Moritaet). Each stanza of the ballad ends with the words "Often the thing succeeds. But for our George it failed." Stoppel tells Heini to note this text, then offers him a sort of substitute gratification instead of the knife. He invites him to a Communist hike in the country. Heini says, "But won't that cost money?" but Stoppel says, "I will take you, you are my guest." Then, further underlining the fact that the hike is a substitute for the knife, Stoppel goes on to list its charms just as Heini in the previous sequence listed the charms of the knife. They will have tents, they will play, they will bathe. Heini agrees to meet the Communists at the railway station the next day. ${ }^{21}$

The preliminary build-up of the family structure is now complete, and a link between the two parents and the political background has been constructed. The position which the film has so far achieved may be summed up in Diagram $1 .{ }^{22}$

The first fifteen minutes of the film have been devoted to building up Communism into a straw man. The audience has been led to accept unconsciously the premise that the symbolism of the family is applicable to the political scene by being shown how this symbolism could be used to create a sympathetic basis for Communism. Heini's world is shown as split into two great halves by the scene of violence between the two parents. Heini himself is repulsed by his father's violence and dependence. He has just been shown a side of his father's character with which he cannot identify, but he is attracted by his mother, who smiles upon her hero. Communism has been quite definitely linked with the world of the emotions in two ways, first through Stoppel, the Communist, who is associated with the mother, vis-à-vis the father, and second, through the knife and the fair. The mother opened the window and let in the music of the fair, which reminded Heini of the knife, and then she gave Heini the money to get the knife in the fair. The link between the fair and Communism has already been discussed in the analysis of backgrounds, and it is accen- tuated by the clear symbolism of the incident in which Stoppel jumps onto the merry-go-round from which Gerda, the seductive Communist girl, has called to him.

This diagram is, of course, fundamentally false. The propagandist has deceived the audience into accepting links which are psychologically unsound. In particular, the knife as a symbol of virility cannot really be linked with the mother, and the film will go on to destroy this preliminary picture. The basic premise, however, will remain, and remain unconscious - that the symbolism of the family is relevant to political ideology-but the symbols will be rearranged.

At this point the story jumps to the railway station where Heini joins the Communist hike. The scenes at the station and in the woods, in which the contrast between Communism and Nazism is built up, have already been discussed. But there are a few points relevant to the family in these sequences. The first of these concerns not Heini's family of origin, but his courtship and the sort of family in which he might be a father. Gerda, the Communist girl, grabs Heini around the neck as he enters the compartment on the train, pulls him down onto the seat, and kisses him on the mouth. While she does this Gerda is wearing a boy's cap, which she takes off after the kiss. Heini is shocked and disgusted by the kiss and apparently still more shocked to discover that she is female. He says, "You—you are a girl?" She replies, "Yes, you seem to notice everything." (See- Figure 7.)

Later, after Heini is disgusted by the Communists, he wanders away from their camp and sees the Nazis celebrating the summer solstice. They find him and think he is a spy. Fritz, the boy leader of the group, recognizes him as one of the Communists who were on the railway station and abuses him and sends him away. Ulla, Fritz's sister, is heard expostulating with Fritz. She is not shown on the screen but we hear her voice telling Fritz that he ought not

\section{Diagram 1}

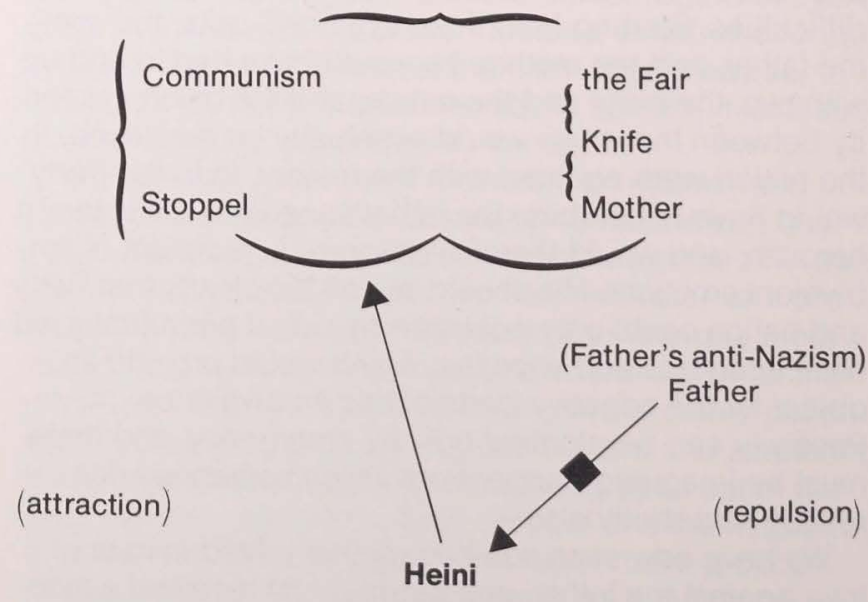




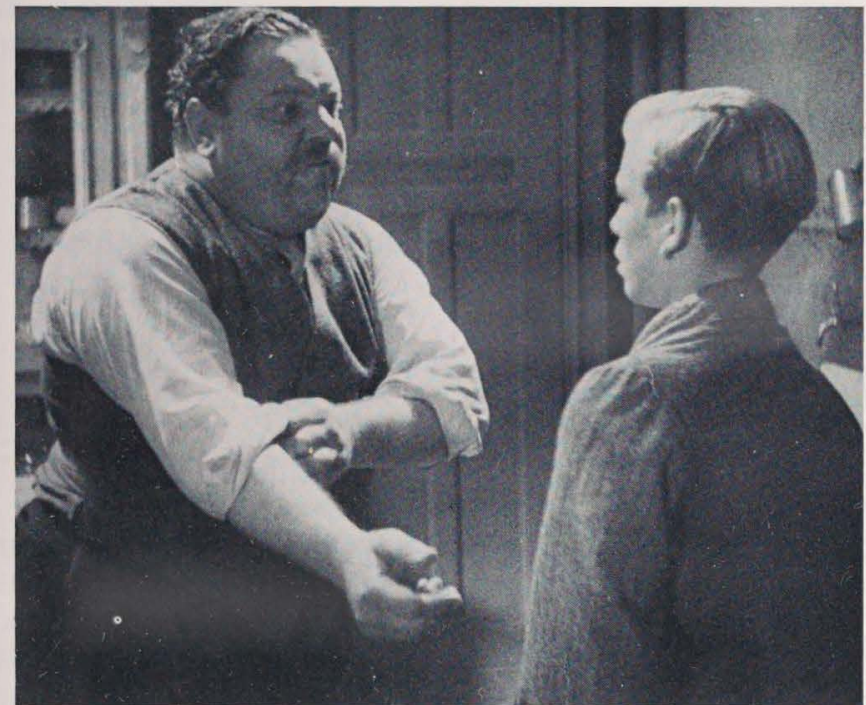

Figure 9 Heini's father forces Heini to sing the "Internationale."

to have been so hasty. Perhaps Heini might have become a Nazi. These two incidents, Gerda's kiss and Ulla's expostulation, provide the beginning of Nazism's answer to the adolescent's problem of sex.

Next morning there is a symbolic reference to Heini's family of origin. While Heini is looking longingly at the Nazis, who are now inaccessible, Stoppel comes through the woods looking for him and calling his name. Heini hides in a hole in the ground and then runs down the hillside to a road where he gets a lift from a truck and goes home to his mother. The hole in the ground is probably a piece of conscious symbolism introduced by a propagandist who had read a little folklore and who wanted a maternal symbol for blood and earth (Blut und Boden). That Heini should hide in this way from Stoppel is the first indication we are given of the complete reshuffling of the symbolic roles which is now about to occur. Formerly Stoppel was linked with the mother vis-à-vis the father. Now we see Heini hiding in the hole vis-à-vis Stoppel. Similarly, the return to the mother now that Nazism has become inaccessible is another indication of the same reshuffling.

When he arrives home his mother is surprised to see him so early and asks him about the hike. Heini is enthusiastic, and she asks, "What then did Stoppel do (to make the trip so successful)?" Heini says, "Mother-but I was with the others-with the boys with the -the hooked cross." His mother says, "But not with the Nazis!" And when he says "Yes," she heaves an anxious sigh; she is not angry but rather regretful. Heini says, "But mother, they are not so bad. They cooked and they wheeled and they swam and they sang a song"-and Heini then sings the "Hitler Youth Song" to his mother.
The father, meanwhile, is reading a newspaper in the next room. The mother must certainly have been aware of this, but she does not warn Heini. At first the father smiles when he hears his son's voice, but suddenly he hears Hitler's name and rushes in, furious. The mother tells him to leave the boy alone and even tries to pull Heini away from his father. The father holds Heini fast and compels him to sing the "Internationale," slapping at his face with each beat of the song. The mother, almost crying, stands there helpless, and a special close-up shot is inserted into the sequence to show us the mother rubbing her own cheek with her hand - thus underlining her link with Heini. This slapping of Heini's face clearly echoes the earlier slapping which was administered to the boy who stole the apple, and we may suppose that this second slapping is likewise administered to "all you who are here"-i.e., the audience. The final shot of the sequence is a close-up of Heini's weeping face (Figure 9).

This violent scene completely destroys the alignment shown in Diagram 1. At that stage of the film Communism was in the mother's half of the diagram, but now with every slap of Heini's cheek we are told that Communism is the father and especially that it is all that is violent and shocking in that parent. The mother is as yet only very slightly associated with Nazism, though already we are in a position to feel that such pro-Communist sentiments as she professes are due entirely to thit father's influence. This indeed is the great difficulty with this German mother. Heini cannot get her to himself unalloyed by her allegiance to the father, and while she is not angry with him because he goes with the Nazis, she is regretful and does not trouble to save him from detection.

The new alignment can again be stated in diagrammatic form. The situation is, however, somewhat more complicated than it was in Diagram 1. And it is now necessary to draw two diagrams, one representing the point of view of the mother (Diagram 2) and the other representing Heini's point of view (Diagram 3):

\section{Diagram 2}

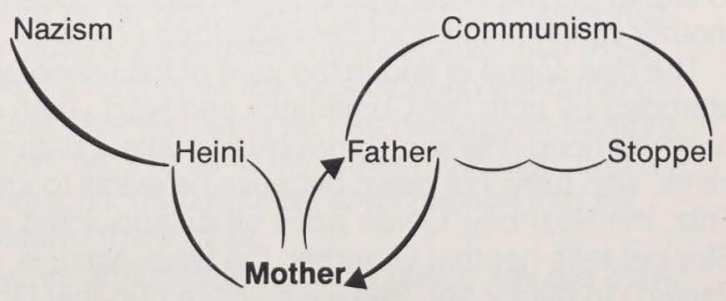




\section{Diagram 3}

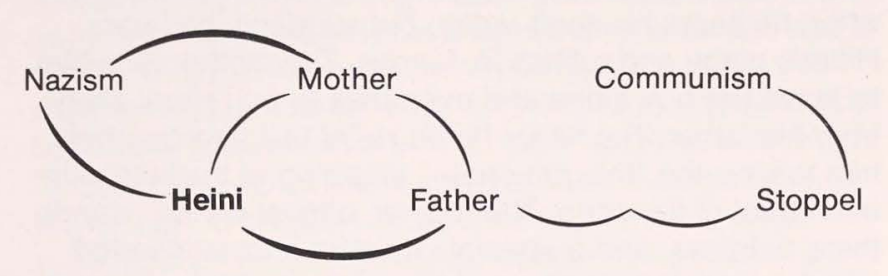

Diagram 2 shows that the mother has no clear allegiance or attraction uncomplicated by repulsion. In psychological terms, all her relationships are ambivalent. Even her love for Heini is complicated by the fact that Heini is linked with Nazism. She herself is not actively anti-Nazi but, duty bound to her husband, must oppose it, so that the arrow representing the repulsion she feels for Nazism is really an echo of the attraction which binds her to her husband. However, her relationship to the father is also ambivalent, and the repulsion she feels for him, while partly her response to his violence, is also partly an echo of the attraction she feels for Heini.

From Heini's point of view (Diagram 3), the position appears at first glance to he much simpler. He is attracted by Nazism and by his mother, and he feels repulsion for his father, Stoppel, and Communism. If only his mother felt as he does, life would be simple for him, but unfortunately the "Mother" (in Diagram 3 ) is a complex being whose attitudes are shown here in more detail. Heini cannot be fully united with his mother because of political sentiments induced in her by the father. The propagandist has built his lesson into the structure of the family where the audience will absorb it without knowing what they are absorbing. Earlier in the film, when the mother slowly smiled on her hero and gave him money which she had refused to the father, we were given a taste of how sweet the world might be if only mother love were unmixed, and now, by contrast, the propagandist is able to slip in his message that Communism is those flaws in mother which result from her undivided (?) love.

The next scene is laid in the yard of the school which is attended by both the Communist and Nazi youth of the neighborhood. We see Gerda try to make a date with Heini, who turns her down because he wants to approach Fritz, the Nazi boy. Gerda goes off disappointed and Stoppel tells her that Grundler, the weak Nazi, is due (faellig) to fall for her. She says with a pun that Grundler does not attract her (gefaellt mir aber gar nicht). Stoppel says that that is not important. She must go ahead and vamp him (einzuseifen, "Soap him in"). This she proceeds to do and we are thus given to understand that the sexual seductions of Communism are not only dangerous but actively treacherous.
Heini meanwhile has been waiting for Fritz, and when he tells Fritz that he wants to join the Nazi troop, Fritz says, "Famous!" (fabelhaft), and takes him to his home.

We then see Gerda falling into step with Grundler on their way to the fair, and Heini falling into step with Fritz on the way to the latter's upper-middle-class home. At the door, Fritz invites Heini to eat with them, mentioning that his father is away at a doctor's conference. (None of the committed Nazis have visible parents, and we shall see that the propagandist's use of the emotional forces of the family to give intensity to Heini's conversion is, in the end, totally destructive of that family.)

At this meal Heini meets Ulla, who shakes hands with him with a conspicuous show of frankness and then cooks eggs for the two boys. While they are eating, Fritz invites Heini to the opening that night of the troop's new "home" (Heim), or clubhouse. Heini exclaims, "A real home!" in a tone of longing which recalls the whole torture of Heini's real home and suggests the possibility, which is to be worked out at a later stage of the film, of completely substituting Nazism for family life. At this stage, however, Heini sees a difficulty-how will he be able to get back into his parents' house after the meeting when he has no house key? Fritz replies, in the slogan of Nazism, "If you will, you can do much" (wenn Man will kan Man vieles), and Heini replies, "Yes, I shall come."

In the following sequence we see Stoppel getting the father's signature to a paper entering Heini in the Communist Youth International. The mother suggests weakly that they ask the boy whether he "will," but the father violently exclaims, "What do you mean, 'will'? There is no more to be said. He can be glad that they accept him. Call it rather luck" (Glueck). And he signs the paper. At the beginning of the film, when Stoppel first approached the father to get Heini for the Communist Youth, the father rather pointedly told Stoppel to approach the boy himself. Now, the propagandist deliberately draws the reverse picture, either to correct an impression of the father's kindness, which he did not intend should remain, or else to give us a total picture of the father's personality, in which we see him as mild only when he is certain of getting his own way, but violent and overbearing when opposed.

Heini now comes home from his meal with Fritz and Ulla. He sees Stoppel just leaving the house and anxiously asks his mother what Stoppel has been doing. The mother weakly says, "Yes, he was with your fatherFather will tell you. Go on in." Heini, a little afraid, goes in to his father, who tells him he is to go to the Party Local that night at 9:00 o'clock. Heini says, "And do I get a house key then?" And the father replies, "Of course you get a house key. You are entering the Party and now you are grown up-a grown man. And a grown man has a house key." 


\section{Diagram 4}

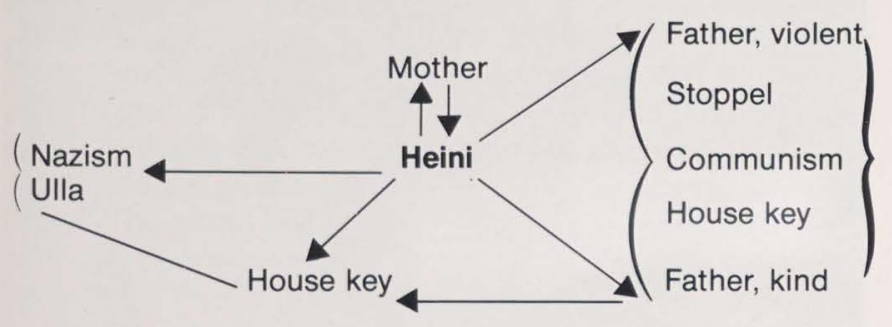

Fumbling to free the key from his ring, the father then makes a long speech, awkwardly groping for words but fully expressing an extraordinary warmth of feeling for his boy. "Sit down a minute - I have wanted to have a word with you-you see, there is much happening in these days that you don't understand-but we, Workers [Proleten], we must look after our own skins. That's it. Look how we live here-your mother, you, and I-it was not always so. We had better days formerly. But now we are thrown out of our tracks [Geleise]. I'd have liked to do more for you. Many a night I have racked my brains how I could make things better for you. But now work for years on end - no wages - that's what breaks one. And now even you young people must help us - must stand by us old ones. Else we'll never get on, do you see? Else we'll be stamping [on a relief line] forever. You understand?" "Yes, father." "Now-you have the house key. Your father is your friend [meint es gut mit dir]. Now, go along and see to it that you enter your Party."

This scene is in a sense a recapitulation of the whole story. The film has carried its audience through all the combinations of the family alignment and has built up by implicit reasoning the notion that all the psychological forces in the family are linked with Nazism, while the unpleasant are due to Communism personified in the violent and childish elements of the father. Now the film goes on from its depiction of the internal structure of the family to invoke on the side of Nazism all the emotions which can be aroused in the boy when he achieves adult independence of the family. We are told almost in so many words that the house key represents responsible maturity, and this symbol is sufficiently well known in Germany to stand alone even without the father's words, "A grown man has a house key."

In this new beginning, the film again gives Communism a favorable opening, and the trap is baited exactly as it was in the first scenes, except that instead of posing as a hero in saving his mother, Heini is now invited to save his father ("us old ones") and the symbol of virility is changed. Instead of a knife, he is offered a key.

Heini comes away from this talk with his father almost weeping. He sits down beside his mother and lays his head on his hands. "Father is not so bad, mother-father is quite different, quite different [ganz anders]. What am I to do now? He gave me a house key and now I cannot lie to him any more. What am I to do, mother? Tell me."

In this speech, Heini echoes his earlier speech about the Nazis - with exactly the same emphasis he told his mother that he had been with the "others" (andern) and that those others were "not so bad." Thus, the moment the father begins to show a pleasanter side of his character, the propagandism takes steps to link this pleasanter side with Nazism.

The mother weakly replies, "It would be good if you would obey [folgen] your father." Heini says, "But I cannot." The mother says, "One can do everything, even if it is painful [Man kann alles. Muss dir eben Muehe geben]. One cannot always do as one would like [gern moechte]."

This last speech apparently recalls to Heini the full strength of Fritz's challenge ("If you will, you can do much") and he says definitely, "I will not go to the Communists. I will go to the others."

The father's change of tone and Heini's decision to use the key to go not to the Communists but to the Nazis have introduced important changes into the alignment, and a new diagram (Diagram 4) must now be substituted for Diagrams 2 and 3.

Heini has placed himself in a false position, and instead of the cmparatively simple alignment shown in Diagram 3, we now have one in which almost all of his relationships have become somewhat ambivalent. His relationship with his father, which was one of simple repulsion, is now mixed, and we can represent it only by showing the father in two separate parts of the diagram- the remembered violent event in one place and the gentle, warm father in another. Even with this division of the father into two personalities, Heini is still left in an ambivalent relationship to the friendly father. "I cannot lie to him"-but Heini is going to lie to him and this lie must necessarily introduce a negative element into his attitude toward this new, kind father. And this negative element is not the simple hate we feel toward those whom we dislike and fear, but the subtler guilt we feel when we take a course contrary to those who love us and whom we love.

His attitudes toward the mother are similarly complicated. Insofar as he now loves the kind but Communist side of his father's personality, he must also love those elements in his mother which weakly echo the father's policies. But these elements he has decided to trample, so that his decision to lie to his father must also, and for the same reasons, introduce an ambivalence into his attitudes toward the mother.

Similarly, his attitudes toward the house key are confused in that the key is very clearly linked with Communism, but he proposes to use it in cooperation with Nazism. The key, therefore, also appears twice in the diagram. 
Of all his relationships, only that toward Nazism remains almost uncomplicated. The attraction here is even stronger than before, since Ulia has now been added to the picture, but even here his attitude is simple only insofar as his "I will" is absolute.

We now have a long series of sequences dealing with Heini's adventures outside the family home, but these sequences must be followed in this family analysis since their structure is evidently determined by the fact of Heini's lie. Heini is stopped on his way to the Nazi "home" by Stoppel. The Communists are about to raid the Nazis, and Stoppel says, "It is good that you have come-now you can join us." He draws Heini onto the porch of a house and they stand there waiting for the raid. We see Gerda try to seduce Grundler away from his post as sentry, and we see the Communists creeping up in the dark from different directions. ${ }^{23}$ Just as the raid begins, Heini dodges away from Stoppel, but he runs straight into the arms of the police who have come to quell the disturbance.

The police have already been characterized in a beautiful shot near the beginning of the film. In the food riot the apples are scattered, and we see a little girl eating one of them in the middle of the street. Two policemen dash up on horseback, as though about to ride over her. She quietly continues to eat her apple, and the police halt their horses harmlessly on each side of her. This shot has told us that the police are supposedly infinitely reliable and impersonal, and since it is their relationship to a child which is used to characterize them, we are justified in saying that they are in some sense parental. (Figure 10.)

Heini is taken to the police station and questioned by these parental police. He refuses to give his name because he is afraid it will get into the newspapers, but he says that he had nothing to do with the affair - that he was on his way home (nach Hause) when the police picked him up. The police agree that he does not look like a gangster (Revolverheld) and tell him to "go home to the mother." The first payoff of his lie is that the police label him child.

As he leaves the police station, he encounters the Nazis and especially Fritz. They accuse him of setting the Communists on to them. Fritz's facial expression in this scene is a study in what Nazism stands for. His lips are drawn back to show both canines in complete and savage repudiation of all human contact with Heini. It is, however, interesting that the Nazis should have been willing to show us this expression on a Nazi face and directed against the hero. ${ }^{24}$ The second payoff of Heini's lie is that the Nazis label him traitor, putting him back to that earlier state which he fell into when he was caught watching the Nazi hike and accused of being a spy. Nazism is again inaccessible, as it was then.

We see no more of the events of that particular night, but this omission is significant. Heini must have gone home and something must have been said at home about

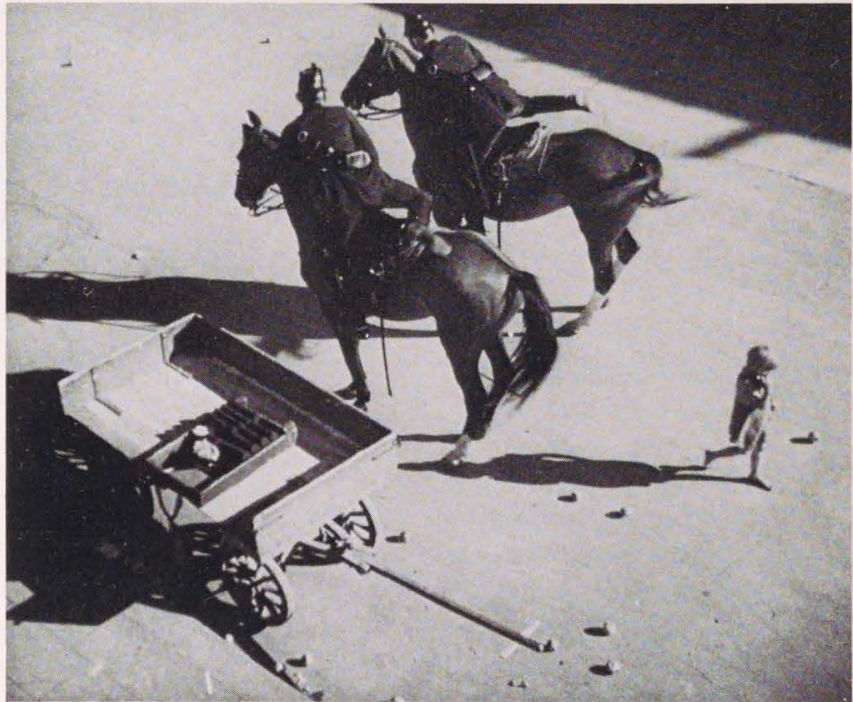

Figure 10 Mounted police arrive to quell the food riot.

the raid, but the filmmakers do not take Heini home. To take him home would have involved them in working out and recognizing the unacceptable implications of the particular symbol chosen to represent maturity and the achievement of independence of the family. That key, the symbol which stands for all this, is a tool for returning to the family. Its symbolic meaning is: "If you will accept responsible sexual maturity, you need not break with your family background." Thus in letting the father give Heini a key, the filmmakers have unconsciously left open an alternative to Nazism. This alternative they avoid by passing over without a word the other events of that night. What did Heini and his parents say to each other when he got home? The film does not tell us and assumes that we will not notice the omission.

The film now jumps to the following afternoon, and we see Heini at work in the printing shop. Stoppel enters and compliments him on the way he conducted himself last night in refusing to give information to the police. The third payoff of Heini's lie is that Stoppel hails him as a hero. Stoppel goes on to say that tonight Heini must join them in "finishing the job." They will get their "bonbons" -dynamite and hand grenades-from the secret cache in the old factory in the Marschstrasse. Heini protests, "I will not that you do this-You must not laugh-I am fully determined (es ist mein vollen Ernst) - I shall warn them." At this threat, Stoppel suddenly becomes serious and tells Heini that that is something which one does only once. Heini says, "This then is that once." Stoppel stares at him for a moment and then relaxes suddenly with a smile, saying, "Lad, you're on the level [Junge, du bist richtig] - I'll see you at 6:30." ${ }^{25}$ 
Heini has now, like Hitler, told his enemies what he will do, and he has succeeded in not being believed. Stoppel has dismissed the possibility that a mere boy would commit a mortal sin. The assumption implicit in this scene seems to be that the older generation (i.e., the enemy) will always let you get away with murder if you tell them that you are going to commit it and especially if you underline the generation difference between yourself and them. The same theme was implicit in Heini's interview with the police, when the inspector ignored the evidence in favor of Heini's guilt in favor of his impression of Heini's childishness. (The same theme is also to some extent implicit in Hitler's war against the "senile" democracies.)

Heini's lie has now been expiated by telling Stoppel that he will warn the Nazis, but the daydream that Nazism is inaccessible persists. As soon as Stoppel leaves, Heini rushes to the telephone and rings up the home of Fritz and UIla. Ulla answers and Heini passionately tells her about the plot and the cache of dynamite. But Fritz is in the room with her and asks who is telephoning. She tells him it is Heini and Fritz says, "That spy! It is a trick. Hang up!" Ulla hangs up the telephone thoughtfully, saying to Fritz, "but he said 'dynamite.'" Heini is left talking to a dead phone.

He dashes to the police, but the inspector says, "My constables are not nurses for your Hitler boys." Next, he runs to the house of Fritz and Ulla, but they are out, and finally he goes to the fair to try to find Stoppel. At the fair, the action of the film is delayed while we listen to fifteen and a half lines of the ballad singer's performance, one of the longest consecutive speeches in the whole film. At the end of the second stanza, as the ballad singer is saying, "Often the thing succeeds. But for our George it . . . ." the explosion occurs, in the Marschstrasse. All the explosives have been destroyed. The Nazis have done it. The Communists know that someone has betrayed them-and Heini goes home smiling and whistling the "Youth Song."

In fact the inaccessibility of Nazism was only a daydream: Heini's warning was effective and Ulla must have prevailed on Fritz. Ulla's role as a personification of Providence has already been discussed in the analysis of German time perspectives, but here we have to note specifically that this role is given to Heini's future mate.

After the explosion, there follows a curious scene between Stoppel and Heini's mother. In all the remainder of the film the dialogue is perfectly straightforward, but in this one scene we have a series of misunderstandings and things half said. It is night, and Stoppel comes beating at the door. The mother tries to keep him out, saying "My husband is out! What do you want? I tell you my husband is out." Stoppel forces his way in and tells her to put out the light. She does this hesitatingly and asks Stoppel, "Why are you looking [glotzen] at me like thatare you being followed?" Stoppel says, "Yes, by the Homicide Squad." The mother then gets the idea that Stoppel has commited a murder, and he goes on to say

\section{Diagram 5}

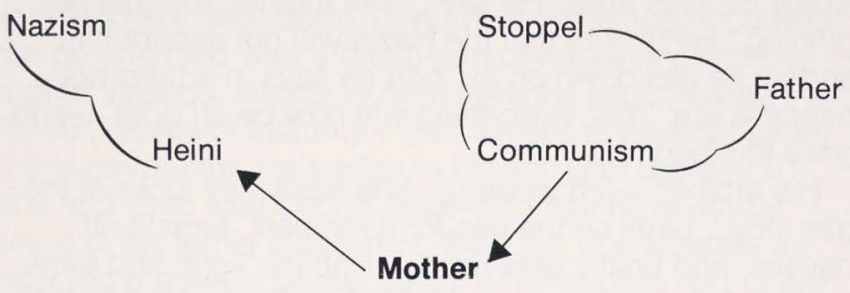

that he will always kill when he is betrayed - that he has been betrayed by the Nazis-"And where is your Heini?" The mother then jumps to the conclusion that Stoppel has killed Heini. She grabs a knife from the table and attacks Stoppel, who easily disarms her, saying, "You ought to be glad that you are not Heini." The mother then asks who betrayed them. Stoppel answers, "Just a stupid boy," and goes out. The mother is thus left afraid of Stoppel and Communism but still uncertain of what has happened.

The effect, and perhaps the purpose, of this scene is to shift the alignment shown in Diagram 2. We saw there that the mother's allegiance to the father made it impossible for Heini to get her complete love. Now this difficulty has in some sense been removed. The mother's allegiance to the father is now replaced by hatred and fear of Stoppel and Communism. In terms of the diagram, the triangle Father-Stoppel-Communism has been turned around so that, instead of the corner representing the father being directed toward the mother, Stoppel and Communism have come into the foreground of her attention. (Diagram 5)

The scene, however, is an awkward one. Stoppel's acting, never very good, leaves more ambiguity in it than the filmmakers perhaps intended, and it is possible to see in the sequences a hint of potential sexual attraction between Stoppel and the mother. ${ }^{26}$ What exactly the filmmakers intended in this scene is not clear, but we have to remember that Stoppel is later to appear capable of conversion to Nazism. The filmmakers therefore had to work within narrow limits. Stoppel could not be frankly vilified; he could not come in seeking to kill Heini-and yet a scene was necessary to make the mother afraid of Communism. The scene consequently built up on misunderstandings and half-understood threats.

Immediately after Stoppel's exit, Heini comes in and the mother says, "Did you do it, Heini?" Heini answers, "Yes, I rescued the boys! . . Why are you crying, Mother?" Earlier in the film, Heini rescued his mother from his father and tried to prevent her from being so sad Now he has rescued the Nazis from the Communists, and she weeps. 
The mother pleads with Heini to go and be reconciled with (versoehn dich mit) Stoppel, "else all is finished [sonst ist alles aus]." He says, "But mother, it is just beginning." He is sure that the Nazis will not accept him, and as he lies down on his bed he says in a tired but happy voice, "Yes, everything will now be all right"-and goes to sleep.

His mother is left weeping. She hesitantly looks at the gas stove, turns on the gas for a moment, turns it off, pauses, and finally gets up, turns off the light, and turns the gas fully on. The music, based on the first bars of the "Youth Song," modified and slowed down to express terror or threat, mounts slowly, and the gas fumes begin to appear on the screen as wisps of haze. Finally, the screen is completely blotted out with these billowing fumes, and the music evolves from terror to a triumphant and almost martial climax. Heini is finally united with his mother and with Nazism-and the propagandic use of the family has now finally broken that little group.

In place of the sharply defined diagrams which we have so far been able to draw of the attractions and repulsions within the family, we have now the billowing haze in which the mother, Nazism, triumph, and death are indistinguishably blended together.

Heini, however, does not die. The gas fumes clear from the screen and reveal Heini awakening in a bed in a hospital where he is being looked after by a middle-aged nurse. When he realizes where he is, he asks about his mother, but the nurse only tells him to drink his milk.

The sequence is then cut to show the father, who is now being looked after by a neighbor who brings him food and opens the window to let in some fresh air, as the mother did at the beginning of the film after the violent scene with the father over the money. The double role of the mother has in fact been divided between two women -one to look after Heini and make him drink the milk, and the other to look after the father.

Returning to Heini, the nurse enters and says, "There is someone to see you." Heini says, "My mother?" The door opens and Fritz enters, accompanied by UIla and four Nazi boys. The Nazis are thus brought in as the word "mother" leaves Heini's lips.

Fritz makes a speech to Heini asking forgiveness for the way they behaved to him at the police station and inviting him to join the troop. Ulla comes forward and presents Heini with a parcel. He opens it and finds in it a beautiful new Nazi uniform with, in one pocket, some money which has been contributed by the group, and in the other, a photograph of Ulla with her brother Fritz. Heini puts on the cap of the uniform, and Fritz produces a mirror from his pocket so that Heini can admire himself -a knight in shining armor with the symbol of Aphrodite in his hand.

The nurse returns to tell the Nazis that visiting time is over, and when they have gone, she removes the Nazi cap from his head while telling him that his mother will never come. Thus, in this scene Nazism is twice substi- tuted for the mother-first when the Nazis enter in the mother's place, and second, when the Nazi cap and the mother are simultaneously removed.

In the next scene we see the father selling part of the furniture in the home. He receives 30 marks for this, and then agrees to sell the rest of the furniture for another 30 . The second sum is counted out into his hand, and then he sees the men removing Heini's bed-the last possibility of Heini's returning to his home. The father tries to stop them, but the bed is already sold. In helpless anger, he flings the 30 marks on the floor-probably evoking in the audience an almost unconscious echo of Judas and the 30 pieces of silver. ${ }^{27}$

Some days later, Heini is still in the hospital and we see him walking forlornly in the garden. The doctor remarks that his recovery is slow, and the nurse replies, "He cannot forget his mother"; and we see him refuse to play with another boy in the hospital garden.

Meanwhile, Heini's father is in the waiting room of the hospital, and while he sits there slumped heavily in his chair reading a fashion magazine, the district leader of the Hitler Youth comes in and sits down in the next chair. The father eyes the swastika on the leader's sleeve and moves away. The leader and the father meet, however, when the nurse comes in and announces that Heini is in the garden. Both of them rise. There is an awkwardness as they both go toward the doorway, and the father says, "Where are you going then?" and the leader replies, "To Heini Voelker." "What? To my son?" "Oh, are you the father?"

When they reach the garden, the leader waves to Heini with enthusiasm while the father greets his son a little gruffly. The father says that the doctor has given Heini permission to leave the hospital whenever he wishes, but Heini says, "But where should I go?" The father says, "What a question! To your father, of course - where you belong [hingehoerst]." At this point, the leader cuts into the conversation with "That is the question-where does the boy belong today [heute]?"28

We have seen Nazism equated with the mother. Now we have a triangular scene, whose structure is revealed by Heini's sitting between the two older men so that they are in analogous positions relative to Heini, though arguing in opposite directions. Thus Nazism comes to be equated not only with the mother but also with the father, as it was when Heini said of both the Nazis and his father, "They are not so bad." Nazism is ready to be substituted for those aspects of the father's personality which are congenial. 
The scene consists of a long ideological conversation, the function of which, in the plot, is to formalize the shifting of Heini from the family setting into the Hitler Youth organization. This conversation must be given in detail:

Leader: That is just the question-where does the boy belong today? I had very good parents. But when I was fifteen I got out of the rut (bin ich ausgerueckt). I wanted to go to sea - to become a sailor-to wherever there were islands, where there were palms - to Africa. In there thousands of boys have left the rut.

Father: $\quad$ And there were bad boys (Lausejungens).

Leader: Boys are something that is wonderful! Boys are a great mystery (Geheimnis)! In all times it has been so. They have run away to the gypsies. Always a day has come and they have joined the great caravan (Zug). They, they begin to wander. Where does a boy belong? You-ask your own boy.

Father (to Heini): Well-you-you say a word now. (Heini smiles to himself, imagining the palms, the islands, and the wandering.)

Leader: I don't know whether you were in the war (im Felde).

Father (resentfully): Yes-indeed.

Leader: Two million boys then freely offered (geme/dt) themselves for service. Every one of them was the son of a father-and, more important, of a mother. And where did they belong?

Father: I am a simple man. I am a worker (Prolet).

Leader: But you must have heard of the Movement (Bewegung). No?

Father: Movement! Attention! March! March! That was my "Movement" till I stopped a bullet. And then I was laid in plaster of Paris, and then there was more "Movement" stretching the bones. Bend! Stretch! Bend! Stretch! And then I hobbled on the stamping ground (Stempel; where men stamp in line, waiting for relief). Week after week, year after year, that was my "Movement." Nothing else "moved" me. I was unstuck (Aus dem Leim bin ich gegangen). Do you think it was eating (fressen) that made me so heavy? And where I belong, that is where the boy belongs. To his class comrades (Klassengenessen).

Leader: You mean - to the International?

Father: Yes, indeed. To the International.

Leader: And where were you born?

Father: In Berlin.

Leader: And where is that?

Father: On the Spree.

Leader: On the Spree. Yes. But where? In what country?

Father: In Germany-yes-in OUR Germany. Think that over.
This dialogue has a rather complicated propagandic structure. The first two speeches are clearly addressed to Heini and to those youthful members of the audience who can be charmed with a daydream of wandering among tropical islands, escaping from parents, and shelving the difficult issues of maturity. Heini himself is clearly caught in this daydream. He smiles to himself with a glowing face and is so wrapped in his dream that he is hardly aware of his father's question. We think of adventure as inducing a greater awareness of other people and of the outer world, but wandering, the escape of the German Youth movements, was different. It was rather a withdrawal into a dream, an introversion of the personality.

It was hardly necessary, perhaps, to provide Heini with this dream because we know that his heart is already set upon becoming a Nazi. But this particular scene is crucial. It is the final scene between Heini and his father, the scene of the final disruption of the family. The propagandist cannot say bluntly that Nazi ideology is logically the bane of the family, that its propaganda is parasitic upon the emotions which dwell within the family, and that, in the end, the ideology is totally destructive of the family unit. Therefore, this final scene must be sweetened, and we are offered the theory that youth has "always" escaped "from the rut" and the lyrical illusion that they escape to palm trees and tropical islands.

The second half of the scene is addressed to the father and to the men of the war generation. Heini and the problem of where Heini belongs fade away almost completely. The leader brings up the question of the war, again and again, "Where did they [the soldiers who fought] belong?" This is tantamount to asking the father not "where does Heini belong" but "where do you belong." In reply to this latent question, the father is then allowed to express all his own bitterness about the war, his own wound, and his own unemployment, and must at the end argue rather lamely, "Where I belong, that is where the boy belongs." The leader ignores this last reference to Heini and pushes the father into equating class consciousness with internationalism (by means of a pun on the word "Internationale"). Then he builds up the trap by dialogue until he can spring it with the words "Our Germany."

In truth, the family drama is finished off with the leader's speech about hunger and gypsies, and in the second part of the sequence, the filmmaker has proceeded to an entirely new task - that of showing that all the principal characters of the film, with the exception of the sinister Wilde, can be converted to Nazism. It is difficult to ensure that every member of the audience will see the story of any film through the eyes of the right character, and whenever, as in this film, two opposing sides are presented on the screen, there is always a danger that 
some members of the audience may see the story through the eyes of some character in the wrong camp. If, however, all the characters make progress toward the side favored by the propagandist, then there is hope that all members of the audience will be encouraged in the same direction.

The father is told to "think over" the fact that he was born in our Germany, and later we see the result of his cogitations. He is drinking with Stoppel and asks Stoppel which he would prefer-English beer or the local Molle Helles beer. Stoppel says, "Molle Helles," and then the father asks, "Where was it brewed?" which leads successfully to "In our Germany - think that over."

Later we see Stoppel trying to save Heini from the vengeance of the Communists; and we see Gerda scorning the traitor Grundler and expressing a preference for Heini. She has taken a first step toward becoming a Nazi in admiring Heini's loyalty to Nazism, and even Grundler himself seems sobered by her scorn.

In sum, by closing off Heini's relationship to his family of origin with this scene, the filmmakers have been able to lay the foundations for the conversion of almost everybody in the film to Nazism. (The family of origin has served its function as a source of emotional intensity, and the propagandist has been able to collect from it all the favorable attitudes directed toward the parents to redirect them toward Nazism while the unfavorable attitudes have been collected and redirected toward Communism.)

\section{Analysis IV: The Future Family}

The family of origin has been destroyed, the mother is dead, and after the scene in the hospital garden, we never again see Heini with his father-but this analysis of the film's use of family symbols must follow Heini to the end, because the beginnings of another family structure are appearing. Every individual whose life is complete has membership in two families, the family into which he is born and that other family which he himself sets up when he marries.

It is clear already that no future family could be set up by Heini on the old pattern. The film has indicated great disapproval of Gerda's lusty sexuality and has frustrated all Heini's symbolic moves toward normal masculine virility - his desire for the knife and his acceptance of the house key presented to him by the father. The old virility has been condemned, and if we want to know about Nazism, we must ask what sort of pattern the film will suggest as a model for the future Germany. In answer to this question the film contains two types of materialHeini's courtship relations with Ulla and the district leader's relationship to the boys. The leader, in the last scene, has been set up as an alternative to the father, and to this extent he can be regarded as a father substitute, so that from his behavior we can get one segment of the future German family pattern while from Heini's courtship we get another.

The scene between the leader and the father is cut off after the leader says, "Think that over," and the next shot shows us the leader and Heini entering another Nazi "home" in the district of Bannheim. Heini is to be protected from the vengeance of the Communists by being removed from the Beusselkietz district. On entering the home, the leader introduces Heini to his new roommate -Grundler. ${ }^{29}$ The leader says, "So, Heini, you will live here. And that is your roommate (Stubenkamarad), Grundler. And this is Heini Voelker-he is alone in the world like you." Thus the leader underlines the notion that Nazism is a substitute for the real home and at the same time marks the parallel between Heini and Grundler. This parallel is at once used, as it was earlier in the film, to point up the contrast between them. Grundler starts to sing a snatch from some popular song:
That is the life of any sailor-
Never think my love will last,
Anchors cannot there hold fast . . .
(Das ist die Liebe der Matrosen- auf die Dauer, lieber Schatz, ist mein Herz kein Ankerplatz. . . . .)

His association with Gerda is evidently causing his character to degenerate, and while he sings he walks around the room with a curiously footloose air, expressing complete casual detachment. He pauses in his song to offer a cigarette to Heini, who refuses disapprovingly. Grundler shrugs his shoulders, lights one for himself, and resumes his song. Heini meanwhile pins up over his bed the photograph of Ulla and Fritz which they gave him in the hospital. Grundler strolls over and looks at this, saying, "So, you have let yourself be photographed with your wench [Flamme]." The insulting implications of this remark are much stronger than we would guess. In most of the German Youth movements-Communists, Social Democratic, and Nazi alike - there was a very strong taboo on any suggestion that ordinary sexual attraction might play a part in "comradeship." It is probable that not only the Nazis but also other groups were on their way toward evolving sexual patterns of the type indicated by the relationship between Heini and Ulla.

Heini replies, "That is no 'wench,' that is the Group Leader [Kamaradschaftsfuehrer] with his sister!" But Grundler says, "To me it only looks like a fine girl [strammes Maedchen] - a very fine girl." We have already had hints that Ulla approves of Heini, and we have seen Gerda's desire for Heini and her seduction of Grundler. Now the fourth possibility of sexual attraction is hinted atGrundler thinks that Ulla is a "fine wench." We are being told that the sort of love which Grundler and Gerda and the Communists affect is different in kind from anything in Nazism. 
The sequence is cut off at this point to show us the scene in which the father tries the trick dialogue on Stoppel with the two pots of beer: "And where was it brewedin our Germany."

When we next see Heini, he is sitting with the other Nazi boys at a meal in the clubroom. Grundler refers to Heini as "our 'Quex.'" Heini protests against this nickname, but the other boys all say that he is a real Quex - a real Quicksilver [Quexsilber]." ${ }^{30}$ They all start to point at Heini and call him "Quex! Quex!" A disorderly fight breaks out between Heini and the others. Heini throws water in Grundler's face, ${ }^{31}$ and in a few seconds one or two subsidiary fights start among the other boys, as though they were all really fighting each other just for the sake of fighting. At this moment the district leader enters and restores order with a single barked command, and the whole scene thus forms a further illustration of the premise that disorderly depravity underlies Nazi discipline. This incident of the nickname requires, however, further interpretation. The name itself- "Quex," or "Quicksilver"- fits well enough with Heini's quick, responsive character, his "mercurial" temperament. But it is interesting that the name should first be applied by Grundler, that Heini should resent the name, and that the name should be allowed to stick-it is later used by Ulla at the highest point of her relationship with Heini, and of course it is used in the title of the film (see Fiqure 6).

We may guess that Grundler's use of the word follows naturally from the contrast which has been drawn between himself and Heini. Grundler is weak and wavering, his heart is no place for an anchor [sic]; but Heini has really changed-he has been converted to Nazism and stands firm in that faith. It is natural, therefore, for Grundler to quiet his own conscience by accusing Heini of changeability. Such a reading, however, will hardly account for the adoption of the nickname in the title of the film. We have to recognize that, in addition to the meaning of mere changeability, the word "Quex" implies a certain sexlessness, or, more strictly, a certain sexuality distilled from the normal lustiness arising from the differences between the sexes-purified until either sex may have the shining, untouchable charms of Mercury or Hermaphroditus. ${ }^{32}$ Such an epithet, bearing these implications, could certainly be applied to the preadolescent Heini, and its overtones - verging on the homosexualwould certainly explain Heini's resentment.

The nickname comes close to being a reproach, and its adoption into the title of the film is best understood as an instance of the rather common phenomenon by which a term of reproach is picked up and worn as a badge of pride-like the Garter and the motto Honi soit qui mal $y$ pense.

If we put together the intersexual implications of the word "Quex" and the narcissistic implications of the incident in which the Nazis give Heini a mirror in which to admire himself, we get a rather clear picture of one side of Nazi character. The badge of reproach is proudly worn, and the uniform is self-admired. This type of narcissism has led to the development in Germany of an entirely new kind of film, which we may call the "pseudodocumentary." These films, of which The Triumph of the Will is the outstanding example, depict historical spectacles such as the Nürenberg Parteitag of 1934, but they differ from ordinary newsreel material in that the spectacle is expressly created and staged for the motion picture camera. Reality becomes a carefully dressed shop window in which Nazism exhibits itself. ${ }^{33}$

The ordinary technical terms of psychology and psychoanalysis are not applicable to the particular type of personality implied by this combination of intersexuality and self-admiration in Nazism. The word "narcissism" suggests not only self-admiration but also effeminacywhich Nazism does not exhibit; and the word "homosexuality" implies dominance-submission relationships, usually with a strong emphasis on the erogenous zones. Nazism has gone to the opposite, and equally pathological, extreme of repudiating all such emphasis. We are of course talking only about the ideal Nazism as it is presented in this film and not about the reality. The film indicates to us that the ideal in 1933 was not merely without emphasis on the erogenous zones, but emphatically anti-zonal, and the psychiatric expectation would be that a cult with such ideals would produce frequent cases of underground homosexuality with pronounced zonal emphasis and dominance-submission patterns following the lines of the overt authoritarian system.

It is, however, the ideal which we are here investigating, and in order to get a clearer picture of the sort of human relationships which would be based on combining narcissism and intersexuality, it is necessary to look carefully at the relationships between Ulla and Heini and between the district leader and his boys. In the last two reels of the film, there are two scenes between Heini and Ulla, and it is interesting to note the ruse which the filmmaker deemed artistically appropriate as a means of bringing this boy and girl together. The script writer has shown considerable resourcefulness throughout the film, and he is here faced with a comparatively easy task, so that we may legitimately assume that the device which here seems to be artistically appropriate is also psychologically significant.

It is the time of the 1933 election, and after a series of shots of election crowds and processions, one very quick shot shows us a crowd scene in which Fritz's head is slightly wounded. Fritz reports back to the Nazi headquarters where everyone is busy working on leaflets. The leader seizes Fritz by the head and gazes into his eyes, then gives orders that he is to lie down. Heini and Ulla meet at the door of the room where Fritz lies in bed. Heini tells Ulla that Grundler has treacherously destroyed all their leaflets and that he is leaving immediately to print a new supply. Heini and Ulla then go off together to print more leaflets in Heini's workshop. 


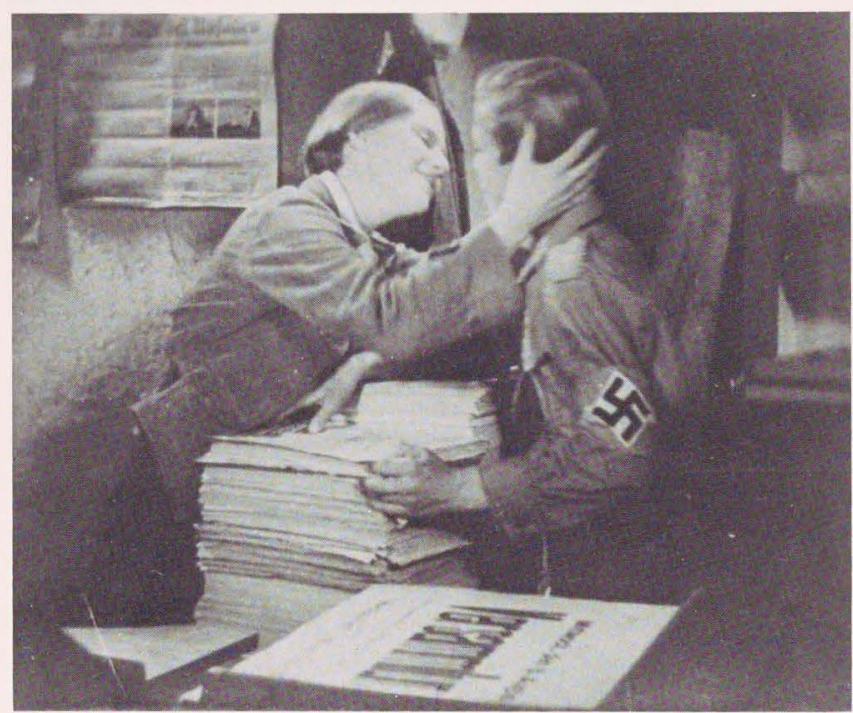

Figure 11 Ulla gives Heini a "Nazi” kiss of friendship.

Thus Heini and Ulla come together by temporary elimination of Fritz, so that Heini is substituted for Ulla's brother. The relationship between them, which is clearly meant to have sexual overtones and to romanticize the mating of pure types under the Nazi aegis, is structurally equated with a relationship between brother and sister.

The second scene between Heini and Ulla is a very short sequence in the printing shop. They have worked all night on the leaflets and finally Heini says, "So-that's done [so das haetten wir geschafft]," and Ulla exclaims, "Quex, you are colossal [du bist ein kolossaller Kerl]," and bends forward, giving him a quick, sisterly kiss-a kiss which contrasts sharply with that earlier kiss Gerda had forced upon his lips. Heini is delighted, and says, "Ulla!- and now for Beusselkeitz!" He then goes out to his death. (Figure 11.)

The preliminary base for the future German family is thus envisaged as a courtship between two mercurial beings stripped of the outward manifestations of sex differences and symbolically equated as brother and sister. Nazism offers us a recipe for life based on regression to those themes against which most of the civilizations of the world have striven since human communities first had culture - psychological homosexuality, narcissism, and incest. This probably is the logical outcome of building a cult on the preadolescent daydream of perpetual youth.

Corresponding to the metamorphosis which courtship has undergone at Nazi hands, we find corresponding changes in the father and son relationship. The film unfortunately does not show us a Nazi father, but we have seen that the district leader is cast as an alternative to the real father, and therefore by comparing him with the father, we may arrive at some indication of what the father-son relationship would look like in the ideal, future Nazi family. When we compare the leader with Heini's father, we find the same sort of systematic contrast that we found earlier in the comparison of Ulla and Gerda. As Ulla is constructed to be the physical opposite of Gerda, so the leader is the physical opposite of Heini's father. He is a curious but not unfamiliar type. The father is a very heavy, broad-faced man, clumsy and fumbling in his movements, his voice a deep bass and his speech broken and halting. He roars when he is angry but he is warm and awkwardly charming when he wishes to be kind. In contrast to this, the district leader is tall and thin, hatchetfaced, fluent and even eloquent in his speech and in his movements. When he is angry, instead of roaring he emits a single, sharp bark. The two men are about the same age, perhaps in their early forties with at most five years difference between them, and yet the district leader is boyish where the father is manly. The leader's youthfulness is enhanced by the uniform he wears which confers upon him the air-slightly embarrassing to non-Nazi eyes - of an overgrown Boy Scout, a Boy Scout who has grown old insofar as the lines of his face are concerned but whose physique has never filled out. He clings longer than he should to a certain boyishness of manner, a certain romanticism of youth maintained almost by recipe after youth should have given place to maturity. In fact, the district leader bears just about the same relationship to the old stereotype of the lower-middle-class father that the ideal sexuality of Nazism bears to the caricatured sexuality of Communism. He is an emasculated father but not an effeminate one. When he talks of the mystery of boys, we are reminded of those nineteenth-century romantic notions about the "long, long thoughts" of adolescence, and yet there is a difference. The nineteenth-century labels were applied to underline a contrast - even a barrier-between male and female, and between the mature and the adolescent, but the district leader's speech and tone indicate rather that he himself is one of the boys whom he romanticizes. He recognizes no such barrier. He shares their dreams and romanticizes himself by some twist of narcissism.

All of this is repellent to non-Nazi eyes, but this is the enemy's idealized picture of himself, and if we are ever to help that enemy pull himself out of the swamp into which he has sunk - and thereby endangered us all — we need to understand him and the dreams on which he has fed. 


\section{Analysis V: The Knife and Death}

Two ingredients of the plot remain to be examined in order to complete the analysis of the propagandist's handling of the symbols which derive their force from the loves and hates of the German family. These are the knife and Death.

The knife is referred to, either openly or implicitly, no less than seven times, and while it only appears on the screen at three of these points, the whole series must be brought together to get a full impression of its significance:

1 The first reference to the knife is in the dialogue between Heini and his mother, after the father has gone off to get his beer. Heini is reminded of the knife by the music of the fair, and turns to his mother. He lists the charms of the knife and begs for money to go and get it. We have already noted earlier that, in doing this, Heini is deviating from the role of the self-sacrificing hero and is doing something which more nearly parallels his father's irresponsible virility. (See Figure 3.)

2 We then see the knife in the fair, and we see Heini lose his money in the lottery. He asks the price of the knife and is told "eight marks." Stoppel appears at Heini's elbow and says, "Now — don't let your head hang so - I promise you'll have the knife sooner than you think-have you thought about it? About the Communist Youth Organization?" and then Stoppel invites Heini to the hike, listing the charms of the hike just as Heini had listed the charms of the knife to his mother.

3 When the Nazis come to Heini's bedside in the hospital, they give him a uniform and tell him to look in the pockets. In one pocket he finds the photograph of Fritz and Ulla, and in the other some money. They tell him that they have all contributed to make up this sum. (There is no overt reference to the knife on this occasion.)

4 When Heini is hiding in the Nazi clubhouse in another part of Berlin, the leader sends him to get some beer. He goes and gets the beer from a bar, and on the way back, carrying two full mugs of beer, he encounters Stoppel. Stoppel makes a last effort to persuade Heini to come back to the Communists and even produces a knife from his pocket, offering it to Heini if he will come with him. Heini's two mugs of beer are in imminent danger of being upset by Stoppel's sudden movements (a little actually spills), but he stands firm against temptation and Stoppel finally leaves him, with the emphatic warning not to show himself in Beusselkietz or he, Stoppel, will not be responsible for the consequences.

5 Stoppel then goes back to the Communists, who are plotting Heini's death. He says, "Whether you want it or notthere it is! [Wer nicht will, der hat schon]," and lays the knife on the table with a gesture dimly reminiscent of Pilate or Judas. The camera then closes in and we see the hands of all the other Communists crowd over the knife. The sinister Wilde lifts the heaped-up but unresisting hands, takes the knife, and puts it in his pocket.
6 When Heini and Ulla are working in the printing shop on the new supply of leaflets, the following dialogue occurs:

Ulla: What will your master say?

Heini: Oh, I will pay him tomorrow for his current [electricity] and paper.

Ulla: Have you money then?

Heini: You all brought money for me to the hospital.

Ulla: Yes, but with that you wanted to buy the knife for yourself.

Heini: Never mind [Ach!]. Leaflets are more important [wichtiger].

7 Hunted and surrounded by the Communists, Heini takes refuge in a tent in the deserted fair grounds. He accidentally touches a grotesque mechanical figure of a drummer, and his touch sets the machine working. It gives a few beats - thus betraying Heini to the Communists. Heini's scream is heard, but no shot, and we are left to presume that Heini was stabbed by Wilde. The knife is seen a moment later on the ground beside the dying Heini.

These seven incidents build up into a definite picture of the psychological significance of the knife. Throughout it is a symbol of the old sort of virility which is imputed to "Communism." Heini's going to get the knife is analagous to the father's going to get his beer. Before Heini appeared on the scene, the father had said, "My boy can just go and get a couple of bottles of beer-Where is the lad?" Thus the two glasses of beer which Heini goes to get for the leader are an echo of the two bottles which he never went to get for his father. The equating of leader and father is again indicated by this echo, but the difference between them is underlined. The beer that Heini fetched for the leader stands for his passivity, which is happily given expression within the framework of Nazism, and this beer, the symbol of passivity, is pitted against the knife - the old symbol of active virility and temptation. We need hardly be surprised that the audience is made to feel anxious lest the beer be spilled, nor need we be surprised that the beer wins against the knife in this symbolic conflict.

Stoppel's handing over of the knife to the other Communists then becomes a statement that he, for his part, is sick of them and has progressed at least from active participation in Communism to neutrality.

The dialogue with Ulla about the money and the knife is of great interest, since there are two obvious reasons which should have prevented the inclusion of this 
dialogue: first, Heini is obviously being a little hypocrite- he has seen the knife in Stoppel's hands and knows very well that it is no longer on sale at the fair; second, the dialogue has an unsatisfactory result - the audience, who have not hitherto been told to associate the money with the knife, now must do so and may well ask what has prevented Heini from acquiring the knife in the interval. We are not told how long Heini spent in Bannheim, but Grundler remarks to Gerda that Heini has been with them there "ever so long [schon ewig lange]." $\mathrm{He}$ could easily have asked one of his Nazi friends to go to the fair and buy it for him.

Thus, by including this little piece of dialogue, the propagandist has let Heini appear to be a hypocrite and has created an unexplained blank in the plot, where previously no explanation was called for. We are entitled, therefore, to conclude that this dialogue was psychologically important to the propagandist.

This importance seems to be of two kinds. First, there is a marked parallel between this weakness in the handling of the knife and the weakness which we have already noted in the handling of that other symbol of maturity and virility, the house key. The propagandist was compelled to pass over the night of the raid on the Nazi clubroom in order not to let it appear that by using the key Heini could combine maturity with a return to his family. And now, again, the propagandist has been constrained to pass over a stretch of time. He seems psychologically impelled to leave open the way to a satisfactory mature sexuality in spite of his ideological trend in the opposite direction.

Second, the dialogue is important at a more superficial level, since it is Heini's formal repudiation of normal sexuality in favor of Nazism and Kamaradschaft. He had, of course, already repudiated the knife once before, in the dialogue with Stoppel, but now he does it again. The propagandist makes him protest perhaps once too often than was quite necessary, but still this second repudiation is artistically appropriate here since it immediately precedes Ulla's kiss. ${ }^{35}$ The abnegation of normal sexuality is rewarded by achievement of Nazi sexuality, and from this reward Heini goes out to meet the knife for the last time.

As to Heini's death, the filmmaker goes to great pains to show us that the Nazis are in no way to blame for it. The district leader has done all he can to save Heini from the vengeance of the Communists by keeping him away from Beusselkietz, hidden in the Bannheim Nazi home, and the filmmaker even goes to the quite unnecessary length of setting up two trains of events, either of which could in the end lead to Heini's death.
The first depends upon Grundler's treachery. Gerda has made Grundler completely subservient to her, ${ }^{36}$ and she and Stoppel find out from him that Heini is in Bannheim. Stoppel does not pass this information on to the other Communists, but himself goes to try to tempt Heini back with the knife, just as we have seen Gerda similarly not passing on the information (perhaps because she is in love with Heini). The train of events, therefore, which the filmmaker could have used to kill Heini if he had wanted to, leads nowhere.

The second train of events springs from Heini's suicidal ambition to return to Beusselkietz. Ever since he has been in Bannheim, Heini has been wanting to get back to his old comrades, and the screen shows two arguments between Heini and his leader on this subject. The leader insists on caution and backs up this insistence with appeals to discipline. He points out that those twelve in Beusselkietz are not the only comrades that Heini hasthat he has "hundreds of thousands" of comrades all over Germany who wear the same brown shirt-and this appeal to the bandwagon and to narcissism prevails in the first argument. In the second argument Heini says, "You said that a Hitler boy is a soldier-and you yourself were an officer in the war. . . and did you forbid your soldiers to advance after the battle was on?" The leader is much moved by this argument. He takes Heini's head in his hands and gazes into his eyes saying, "In God's name, go then to your Beusselkietz."

Thus it is Heini's fault-overzealousness - that leads to his death, so that this, his real death, like the former symbolic death which he shared with his mother, contains elements of suicide: the one was inflicted on him by his mother, the other results from his own Nazi zeal.

Objectively speaking, the final death was inflicted on him by Wilde with the knife, so that the suicidal elements discussed above provide only a partial explanation of the events and must be supplemented by a further explanation. Actually the death is the meeting point of two separate trains of circumstance, the development of Heini's character, on the one hand, and the history of the knife on the other. At the beginning of the film, Heini wanted to possess the knife, the symbol of old-fashioned virility, but on this occasion the knife was denied him, and later, in the interests of ideological purity, he abjures the knife in favor of two glasses of beer-his passivity. This passivity mounts to suicidal zeal and finally, in the end, again meets the old virility symbol, the knife. 


\section{Conclusions}

\section{The Nature of Nazism}

The first purpose of this analysis has been to draw from the film as much insight as possible into the psychology of Nazism, and in conclusion, those characteristics of Nazism which have appeared at various stages of the analysis are presented in the form of a list. Such a listing of psychological characteristics is necessarily a distortion. Every characteristic of a human being is dependent on, is indeed a section of, a whole character. Each item in the list is only a special view of the central Nazi character, brought to light by some special form of analysis. For example, it is probable that the Nazi tendency to project their own failings upon the enemy is only another way of describing the double nature of their attitudes toward sex, and this again is probably only another way of describing their climactic time perspective -insisting, however, that any separation of the characteristics one from another necessarily does violence to our view of the whole. Such a list may still be useful. The whole character cannot be expressed in words, but the list may help the reader to synthesize in his mind some vague feeling or impression of what the whole is like.

The principal characteristics of Nazism are here listed in the order in which they appeared in the analyses.

Characteristics which appeared in the study of time perspectives:

1 In 1933, the Nazis had a climactic view of the future which we summarize as "through death to a millennium." Evidence was produced also for believing that, in 1941, this time perspective was already giving place to its obverse, "though preliminary victories to a final defeat." From these two conclusions, the central hypothesis emerges that Nazi time perspective is reversible and subject to a swing between two extreme positions. It is likely that either of these extreme positions is more stable, more psychologically attractive than the more common-sense middle positions, and also it is possible that indulgence in either of the extremes strengthens in the Nazi soul the potentiality for the other; therefore, while a swing toward the more pessimistic time perspective may bode well for a United Nations victory, the psychiatric problem which Nazism presents is of how the more realistic middle position may be made more stable and the extreme positions less stable, so that the pendulum may come to rest.

2 Nazism is an age grade system. Important educative functions of the family, especially the function of giving to the growing boy some sense of self-sufficiency, are taken over by another set of institutions, the youth organizations and the army. These institutions are divided into a number of age grades, and the psychology implicit in this age grade system is basic to Nazism, so that such a film as this, which does not specially deal with the grading of
Nazi youth, is nevertheless patterned like an initiation ceremony. Thus, at least in 1933, the Nazi attitude toward death included the notion that death is a sort of promotion.

Some sort of age grade system will inevitably persist in Germany after the war, because the large number of broken homes and the general social dislocation will increase rather than decrease the importance of any institution which takes over the educative functions of the family. But it will be important for any such institution to find some new phrasing of its philosophy of death and promotion. The linkage between death and the passage from one social status to another will probably persisteven in commencement exercises in American schools the students often sing Tennyson's "Crossing the Bar"but Germans will have to find some phrasing different from the notion of death itself as an achievement. Perhaps death might be seen more definitely as the sloughing off of the old personality and less as a step toward the new.

3 In Nazi ritual it is assumed that death is followed by multiple reincarnation. This notion has a number of undesirable implications. It necessarily diminishes any sort of dignified and responsible individualism. The individual sees himself as a mass-produced object, identical with a thousand others. He may like this view of himself, and he may reverse the tradition of dead Nazi heros, but his chances of discovering his own worth and dignity, his own power of responsibility, are necessarily reduced.

Characteristics which appeared in the study of political groups:

1 Nazi propaganda continually resorts to projection. The propagandist smears his enemy by attributing to him characteristics which are latent in Nazism itself. Analysis of the various sorts of projection recognizable in this film indicates three fundamental splits in the Nazi character. In each of these splits it is probable that each side of the personality promotes the other, the more extreme positions of the personality being more stable than the intermediate positions. The stability, however, of the extreme positions, especially of the overpurified extremes, is in part dependent upon being able to recognize or imagine some enemy on whom the other extreme may be projected. All three splits are recognizable in the pre-Nazi movies of the 1920s.

a. Between discipline and disorder. Discipline as imagined in the Nazi ideal depends upon extreme passivity -almost an impassivity - in the face of sudden, barked commands, and these commands appear to be the 
stimulus which prevents lapse into disorder. In the Nazi ideal at least, discipline is not so much a toadying to authority as a controlled steadying in the face of sudden shock, whether this shock be a sudden command or an enemy attack. (There is here an interesting psychoanalytic possibility of identification between authority and the enemy, and some identification of this sort would be expected since many of the unpleasant characteristics of the old father stereotype are projected onto enemies. The film, however, does not provide material for examining this identification.)

Psychologically the passivity is wrapped in an aura of romantic heroism, typified in this film by the incident of the mark, in which Heini in one and the same act joins his mother in passive submission to the father and does this act of submission as a piece of rescuing heroism. And the passivity is further romanticized by substituting it for an identification with the father. The lusty and aggressive behavior of the father-his going to get beer, etc.-is replaced in the son by the two glasses of beer which express the son's passivity toward his leader.

The disorderly underside of the coin is typified in the film partly by the momentary outbreaks of disorder among the Nazis, and more fully by their representation of "Communist" behavior. It is a system of behavior characterized by lusty virility and aggression. When the Nazis themselves lapse into this state, they become disorganized, but when they are projecting this state upon. the Communists, they attribute to them a considerable degree of malevolent organization.

The split between disorder and discipline is an old theme of German dreams and nightmares - recognizable in, for example, The Cabinet of Dr. Caligari (1919) - and it has its roots undoubtedly in the stereotype relationship between father, mother, and son. We do not know what the parental relationship looks like in families where the parents grew up as Nazis, but it is here that we must look to determine whether this particular nightmare is likely to persist in Germany and to find the means by which the Germans may remedy it.

b. Between sexual "comradeship" and sexual grossness. We have noted that the overpurified Nazi ideal of sex leans toward the homosexual side even though, in the ideal, the sexual object (Ulla) may be of the opposite sex. On the other side of the picture, we have the sexually gross and heterosexual relationship to a sexual object (Gerda), whom Heini, in the curious incident of the kiss in the railway carriage, mistakes for a boy. In the characterization of sexual grossness, there is an extreme emphasis on the mouth and buttocks, and this emphasis on the mouth spreads from the purely sexual to include gross eating, the throwing of food, and even the use of chewed food as a weapon. On the side of the Nazi ideal, the eating and sexual functions of the mouth are minimized, but the mouth still appears as an organ of aggression in the facial expression of the district leader when he gives his barked commands and on the face of Fritz when he repudiates Heini as a traitor.

The middle position between these two extremes is not represented in any way in this film, but it does appear in some other films (e.g., The Street), where we see a husband tempted away from domesticity by the bright lights and whirl of the city. Significantly, in The Street, the middle position, domesticity, is characterized as dull and almost regressive, in the sense that the husband's relationship to his wife is almost that of a son to his mother.

Essentially this split between an ideal homosexuality and a gross heterosexuality seems to be an expression of preadolescent psychology. It is significant that Heini is a preadolescent and that the audience is encouraged to see life through preadolescent eyes. It is to eyes of this age in German culture that Nazism appeals, and we may suppose that where it appeals to adults, the attraction is a nostalgic longing for a preadolescent purity. It would seem, in fact, that German culture has in some way overvalued that preadolescent period of life and has inflated the romance of this period until it has become a model for the culture as a whole. To correct this, some change will have to be introduced, either into the family pattern or into the pattern of whatever institutions and youth organizations perform the function of giving a boy self-sufficiency and introducing him into adult life.

c. Between light and darkness. This split is, of course, common to most occidental cultures, which associate fear, dishonesty, and vice with the dark, but it is interesting that in this film the split between light and darkness takes two forms: light is used to characterize the Nazi ideal while darkness characterizes the Communists; but also within the Nazi ideal, light and darkness are used to characterize different stages of the step from one status to another. In this way, over and over again the projected and repudiated themes find their expression within the ideal system.

2 Nazism assumes that the individual is in a sense a mechanical object. He is not endowed with free will, or with any internal tendencies toward good or evil, but rather is seen as responding mechanically and inevitably to an external dualism between authority and temptation. This theme occurs in pre-Nazi Germany film material in two forms: we see the mechanization of man in numerous robot fantasies (e.g., Metropolis) and, inversely, we see machines endowed with malevolent semihuman personality (e.g., in Metropolis and Berin). This notion is closely linked with the Nazi idea of discipline, multiple reincarnation, and the whole psychology of the Nazi parade grounds. It is interesting to note, however, that in the twenties these ideas of mechanization were especially spread by filmmakers and writers, who were not themselves engineers. In its origin, the idea was probably in part a reaction to the enormous industrialization of Germany by people who were not actively concerned with mechanics. It would be very important to know how much the en- 
gineers themselves have consciously or unconsciously adopted this fantasy, and perhaps among them there might be people who could correct it. It is also possible that the fantasy has undergone changes in the course of the war, and it will be important to know, for example, what attitudes have developed in regard to the tanks and airplanes against which the Germans are fighting. We (especially the English) tend to think of our own tanks, etc., as tools or vehicles or horses-creatures whom we endow with free will. What attitudes the Germans, who personify their own machinery, have built up in regard to ours is not known.

Characteristics which appear in the study of the family: 1 One of the major appeals which Nazism had for German youth was the solution it offered of the complex and intense emotions implanted in the boy by his pre-Nazi German family background. The Nazis have used the old family background as a springboard for their propaganda, not only in this film but also, for example, in Hitler's account of his own boyhood in Mein Kampf (Erikson 1942). Specifically, in this film we have seen how both father and mother are characterized as mixtures of good and evil, so that the attitudes of the boy are ambivalent toward each parent. The propagandist has rearranged these attitudes so that by the end of the film all the positive attitudes toward both parents become directed toward Nazism while the negative attitudes are focused on the enemy. Thus, the Nazi clubhouse becomes a substitute "home," the district leader is played off against the father, and passivity becomes heroism when it is seen as a means of rescuing the mother.

This complete reorientation of the attitudes and stereotypes which were available in pre-Nazi Germany leads logically and necessarily to the destruction of the old family unit. Thus the obvious and necessary procedure for correcting the German tendency toward Nazism and other such cults would seem to be the resuscitation of the family. The mere resuscitation of the old German family pattern, however, will not be sufficient, since this pattern has been used again and again as a springboard for cultist youth movements. If the pattern were merely resuscitated, it would act only as a stimulus for such movements. The old German family pattern with all its ambivalences may have provided a stable base for German society in the nineteenth century, but it would not provide such a base today. Habits die hard, and today the habit of regarding this old-style family as something to be rebelled against, as an inspiration for revolutionary ideology, is too strong.

The family must be resuscitated, but the roles of father and mother must be modified in some way. The youth organizations, as we have noted above, are likely to persist in the postwar world simply because any organization will be valuable in that period of dislocation. It will be essential, however, that entry into these organizations and membership in them not be conceived as a rebellion against the parental background, and for this to be so the parental background itself must alter.

As to the direction of this alteration, no prescription is possible until we know what the new parental patterns in Germany are, how Nazi-trained young men and women behave toward their sons, what character is today being implanted in small children by mothers whose husbands are away from home, and how the people of Germany will feel about Nazism after the war. It is out of these attitudes and patterns that the solution must be developed, and these patterns should be the subject of intensive inquiry today.

2 In the analysis of the episode of the house key, we noted that the propagandist in 1933 was psychologically unable or consciously unwilling to exclude the possibility of a persistent and satisfactory relationship to the family background. The house key, the symbol which he chose to represent Heini's independence of the family, is itself a symbol for Heini's return to the family, and the film, therefore, must pass over Heini's use of the keys that night. This would seem to indicate that there is available in Germany, even among the Nazi propagandists, a psychological opening for the revival of family life. There is a crack which could admit an entering wedge. If such an opening exists among the propagandists-and the men who devised the script of this film were undoubtedly enthusiastic Nazis - then it is likely that a very large portion of the population of Germany is ready for a return to a world in which the family would again be an important educative institution.

3 The old German interest in ideas of destiny has been picked up by Nazism and become one of the cornerstones of Nazi ideology, but in the process the concept of destiny has changed. In this film the mother, the tragic predictor, dies, and her place is taken by Ulla, who twice works like Providence behind the scenes; and we noted that in another film, Faehrmann Maria, the old masculine personification of Death is killed, and his place is taken by a sexually desirable young woman. We do not know the psychological dynamics which lay down a base in the child for this curious interest in destiny; we only know that this interest is characteristic for German culture and that it has changed. The destiny idea is certainly related to the climactic time perspective we noted above destiny is the climax to which man must look forward, and it is his duty to follow that destiny. We noted above that the German time perspective shifts between two extremes-one optimistic, the other pessimisticand that it would be important to substitute for both of these some more stable middle position. Such a substitution would probably exclude the notion of destiny or would, at any rate, rob this notion of much of its psychological attraction. This attraction is probably the result of those unidentified parental patterns which lay the base for the whole destiny idea, and therefore it becomes ex- 
ceedingly important that these patterns be identified and that they be altered or eliminated in the future German family.

4 In the course of the film, Heini graduates from coveting symbols of virility - a knife and a house key - to wearing a Nazi uniform and admiring himself in a mirror, and this narcissistic theme has been exploited over and over again by the Nazis so that it has become one of the dominant themes in the cult. We may like or dislike narcissism according to our own cultural standards and tastes, but at any international level, we are concerned only to make sure that no nation shall induce in its population a character structure which is inevitably committed to an internationally aggressive role. Some of the most peaceful people in the world are the most narcissistic; the Balinese, for example, are among the most peaceful and the most narcissistic. Warfare and personal aggression are virtually unknown among them, and internationally speaking, they would be ideal neighbors. Thus, narcissism itself is no blemish and may lead to all sorts of cultural achievements. The important factor is what is admired in the self. If the self is admired for beauty or for virtuosity in the arts of peace, then narcissism will promote these characteristics; if, however, the self is admired as a mechanism of aggression, then narcissism must promote aggression. There is, therefore, no reason why narcissism should not even be encouraged in Germany, provided the Germans shift its content and admire themselves for qualities and virtues which will make good neighbors of them.

\section{Learning, Culture, and the Propagandic Process}

Besides the psychology of Nazism, the detailed study of this one film has bearing on a number of other types of problems, which vary from the most general questions about human nature, the ways in which we learn, and the propagandic process to the forms of propaganda which can be carried in fictional films. Our analysis has shown that in this film there are a large number of themesespecially those connected with the family-which are more or less easily overlooked by the casual audience but which nevertheless may have very high emotional force. That those themes are actually present in the film and were put there by the filmmakers, consciously or unconsciously, there can be no doubt. The film itself provides continual verification of this fact. We have seen, for example, that Ulla not once, but twice, acts like Providence behind the scenes so that the significance of this theme is verified by its repetition. Similarly, we have noted that the contrast between Ulla and Gerda parallels that between the father and the district leader, so that all our descriptive analysis of the difference between the Nazis' picture of themselves and their picture of Communism rests not upon one instance, nor yet upon one contrast, but upon two contrasts which mutually verify each other. The material which we have analyzed shows an extraordinarily high degree of internal consistency, which enables us to detect the same state of mind at work in all the various contexts of the film, and so to obtain a real picture of what sort of mind participated in and approved the total creation.

On the whole, this is what we should expect of any daydream or artistic creation-that the way in which the work of art is structured is psychologically characteristic for the creators - and ranged behind this generalization and supporting it, there is the whole mass of our anthropological and psychiatric knowledge of human nature. We know that human beings are generalizing creatures in the sense that they will bring to any new context emotional and intellectual habits acquired in other contexts, and especially those habits that they acquired in early childhood. The behavior of any individual in a new context reechoes all his earlier experiences and forms of behavior. The individual is a single organized entity, not a collection of bits and pieces, and when we watch his behavior and look at his creations, we find running through all the same principles of organization.

The next step from this generalization is to say that a similar character and similar principles of organization will be typical for the various individuals in a given tribe, a given community, or a given unit, and this is vouched for by anthropological findings among primitive peoples and more recently by the findings of anthropologists in the study of the higher oriental and occidental cultures. It is true that, when we are dealing with cultures, the levels of similarity between individuals are necessarily somewhat more abstract, but still we are beginning to be able to define (Bateson 1942) these levels and arrive at a systematic understanding of any given culture in terms of the thematic handling of the various contexts of life.

But this is a propaganda film, and therefore there is a further question we must ask. Granted that the film is structured and built in terms of specifically Nazi themes; granted that the handling of the family, of courtship, and of death are consistently Nazi-these themes are still not articulately stated by the propagandist, and it may be doubted whether the film would serve to propagate these themes. The obvious methods of testing such a question are barely available. Audience research techniques have specialized in examining the reactions of an audience to what was explicit in a film, but themes of the type with which we are here concerned are usually not explicitly recognized-therefore, their effect upon an audience cannot be obtained by direct questioning. There is, however, very strong evidence, especially on the psychiatric side, for supposing that, in many cases, themes which can be accepted so long as they are not explicitly stated may be violently repudiated the moment attention is consciously called to them-indeed, one of the purposes of our whole analysis has been to bring the Nazi themes out into the open where the reader can recognize them and so be fortified against them. 
In place of audience research we must rely on our general knowledge of man as an educable creature and our knowledge of the circumstances under which learning occurs. Simple learning, we know, occurs principally in those contexts which contain elements of either reward or punishment, and it is probably safe to generalize from this experimental finding to the very much more complex type of learning with which we are here concerned - the modification of the individual's character and view of the universe in which he lives, and his reading of the events in which he participates.

We should then have to ask whether the individual member of the audience is rewarded in any way for accepting the themes which are implicit in the film, and whether he is punished in some way for refusing to accept them. Here the answers must be affirmative. It is exceedingly difficult to enjoy a good film without accepting the thematic premises upon which it is based. Either we accept the premises and enjoy the film or we resist the premises and suffer a psychological or physical headache. It is in general exceedingly difficult to maintain any sort of intellectual detachment, to carry along as a part of one's mental state some reservation, while enjoying any form of entertainment. The audience may say to themselves: "This is a very good film"; and they may say to themselves: "But I disagree with the contrast which the film draws between Nazis and Communists." But combining these two statements is exceedingly difficult and tends to result in: "If this contrast between Nazis and Communists were true, this would be a good film." Thus the premise which an audience tries to repudiate easily ends up as a supposition which it temporarily accepts.

The propagandic effect of a film is perhaps stronger when, like Hitlerjunge Quex, the film contains both explicit and implicit suggestions. The audience member who repudiates the explicit contrast between Communists and Nazis may find it exceedingly difficult to repudiate the less explicit propagandic themes which the film contains. His critical sense is focused on one feature of the film, and if he is to go on enjoying the film, he cannot become critical of such assumptions as the way in which Heini's progress toward Nazism is made easy for him by Ulla's intervention.

There is thus an a priori case to be made out for the propagandic effectiveness of themes which are not explicit. The audience is rewarded by enjoyment of the film for accepting these as implicit premises and is, in a sense, punished for refusing to accept them. This case is based, however, upon the structure of simple learning experiments, and it is a very long step from these experiments-from the rat which learns that the sound of a buzzer is the precursor of an electric shock that can only be avoided by lifting the right foreleg - to the more complex learning phenomena with which we are here concerned. The Nazi convert learns to remodel his Weltanschauung, his interpretation of the universe in which he lives, and his interpretation of his own behavior. To compare him with the experimental rat, we should have to suppose that the rat learned not merely to lift his leg whenever he hears the buzzer, but also to expect future sequences of experience to be patterned like the experimental setting; that pain would always be preceded by some warning; and that, for him, the problem of life consisted in trying to guess what magical behavior would avert these pains. Such a rat might be said to have learned not only the connection between a buzzer, lifting the leg, and pain, but also to have learned a Wel-

tanschauung or ideology. Unfortunately, we have almost no data on this order of learning. ${ }^{37}$ That much learning occurs, there can be no reasonable doubt, and it is probable that the generalizations about reward and punishment take less tangible forms, such as the enjoyment of the film or the psychological headache to which we referred above.

The verification of the central hypothesis - that themes implicit in an artistic structure may be propagandically effective-must depend upon the development either of methods of audience testing which will tap unconscious or semiconscious levels, or of learning experiments which will demonstrate this more complex type of learning at an animal or human level.

\section{Acknowledgment}

I thank the following persons for their cooperation: Gotthard Booth, Elizabeth Halbersberg, Hans Herma, Karen Horney, Siegfried Kracauer, Ernst and Marian Kris, and Robert Waelder.

\section{Notes}

1 This study was completed in the spring of 1943 while I was film analyst attached to the Film Library of the Museum of Modern Art. As it is now presented primarily for its methodological implications, no attempt has been made to bring the comments about Nazi Germany up to date. These should be read within the research context of the state of the war in 1945.

2 Lasswell and others have published formal methodological statements and even experimental data on contrasting methods of content analysis. They show the differences in the final findings which result from differences in the size of the unit chosen for diagnosis. In terms of Lasswell's system, the present analysis might be described as an extreme case in which the unit of analysis is the whole film, and in which, therefore, only qualitative, nonstatistical conclusions can be reached.

3 The present study supports a number of the conclusions which Erikson (1942) arrived at by analysis of other types of German material.

4 These data are taken from "Vom Werden Deutscher Filmkunst" by Oskar Kalbus (1935), where a part of von Schirach's speech is quoted.

5 For more detailed and systematic discussion of time perspectives, see Frank (1939) and Lewin (1942). 
6 In translating the "Nazi Youth Song," the word flattern has been rendered as "billow." The dictionary meaning of this word is "flutter," and the German word is certainly sometimes used in this sense (e.g., in referring to birds). A small experiment shows, however, that Americans, when asked to visualize a flag fluttering, usually see a small flag moving rapidly or a large flag rather far away, whereas the image called up in Germans by the words Fahne and flattern is of a large flag close up. In Nazi films, the flags are usually photographed to fill the frame, so that the emphasis falls not on the changing outline of the flag, but rather on the wave motion in the middle of the fabric. This billowing motion is clearly intended to have a fascination similar to that of waves in water.

7 For the Nazi Age Grade system, see Gregor Ziemer, "Education for Death."

8 Unfortunately, we have no data on the symbolism of these ceremonies, but it is almost safe to predict that they contain a mortuary elementcertainly referent to the heroic deed and probably actual symbolic representations of the death of the candidates.

9 The Heimat is an important symbol in Nazi ideology. It differs from the Vaterland in several respects. In particular, the Heimat seems to be a pleasant place to which one returns or dreams of returning, so that the emotion evoked by this word is a nostalgic, rather than a disciplined, patriotism. The word Heimat is feminine.

10 The whole film is, of course, an attempt to make political capital for Nazism out of human woes, and the suggestion that Communists do this is a typical example of the technique and mental state of Nazi propagandists, who project their own characteristics onto their enemy

11 The boy who receives this insult is Grundler, the weak Nazi. I do not know of any psychological reason why he should have been selected for this, unless it be because he is the only named professional actor among the Nazi boys. Heini, Fritz, and Ulla are all anonymous "Hitler Youth," but Grundler is a named actor, Hans Ramspott.

12 The general opinion of informants who were in Germany at this time and in touch with the Youth Movements is that the Leftist groups were slightly more disciplined than the Hitler Youth.

13 An official propaganda photograph of the "Strength through Joy" movement shows that this identical game of Schinkenkloppen is commonly played at Nazi picnics.

14 Actual death in swamps occurs rather frequently in German films. The case of Faehrmann Maria has already been mentioned. And in Friesenet, a girl is punished for sexual relations with a Communist by being led to the edge of a swamp where she must commit suicide. The film suggests that this punishment is traditional among the peasants of this old German colony in Russia.

15 In Nazi youth films, the camera rather frequently provides shots of the backs of the legs of boys, showing the bare inside of the knees.

16 This type of symbolic treatment of temptation is also common in preNazi German films, e.g., Variety, The Street, Sunrise.

17 For several of the suggestions here put forward, I am indebted to conversations with E. Erikson (1942). On the whole, the findings in the analysis of this film coincide very closely with those of Dr. Erikson in his analysis of Mein Kaempf and other Nazi literature.

18 This metaphor is probably put in Stoppel's mouth to prepare us for the association between the fair and Communism.

19 I have to thank Dr. Marian Kris for pointing out the underlying passivity in this episode.

20 The fact that a vase is contrasted with the knife provides additional verification for regarding the knife as a virility symbol, and it also verifies our assumption that the filmmakers had at least a prior acquaintance with theory.
21 Stoppel does not at this stage offer the knife as a reward if Heini will become a Communist, but the possibility is clearly in the air; later in the film this bribe is actually offered.

22 The diagrams used in this analysis are necessarily on a rather crude associational level and fail to indicate the finer points of the various attitudes and relationships. Psychoanalysis is still a verbal rather than a diagrammatic science.

23 It is interesting to note the frequency of encirclement themes in German films. Even in much earlier films (e.g., M, Emil und die Detektive) this theme is recognizable and seems almost to replace the chase themes so popular among American filmmakers.

24 The same expression appears on the face of the district leader when he gives his barked commands to the Nazi troop.

25 This scene is somewhat awkward. Stoppel's acting is not convincing and we are left without any clear idea of why he did not worry about Heini's threat.

26 In the novel on which the film is based, this scene takes place in two parts. First, there is a conversation between Stoppel and the mother, in which the mother is described as hypnotized with fear in Stoppel's presence; later there is a conversation between Stoppel and the father which is overhead by the mother. In this conversation, Stoppel tells the father that he will give Heini one more chance to come back to the Communists, but if he does not take it, he will be killed

27 Echoes of Christian mythology occur rather frequently in German films, usually in a much disoriented form. In the present film, it is perhaps significant that, at the beginning of the film, Wilde, the Communist villain, is allowed to echo Christ, whereas at the end of the film the Communists echo Judas and Pilate.

28 Heute may mean either "today" or "in this period of history."

29 The film gives us no rationalization for Grundler's removal from Beusselkietz to the new district. He was certainly a member of the Beusselkietz troop, under Fritz, in the earlier scenes.

30 So spelled in the Reichfilmarchiv transcript. The usual spelling of the metal is Quecksilber.

31 This is probably an echo of the earlier episode in which chewed food was thrown in Grundler's face at the beginning of the hike. The psychological reasons for this repeat are not clear.

32 This interpretation would not necessarily imply that either the filmmakers or the audience were familiar with the classical myth of Hermes and Aphrodite. It would be equally possible for the name "Quex" to get these overtones from the properties of the metal: its curious "quickness" and its "touch-me-not" behavior, the way in which it shatters into shining pieces when shaken, combined with its power of recovery into a single mass when the disturbance is over.

33 See Kracauer (1942) for a careful discussion of this fake realism in Triumph of the Will and in German newsreels.

34 In an earlier footnote it was pointed out that the relationship between the Nazi party and the nation would not be handled in the symbolic terms set up by this film. It is possible, however, that this in-turned narcissism - whereby the leader is romantic about himself as though he were one of the boys, in spite of the fact that he is also in part a father figure - may provide a partial solution of the problem of reducing three symbolic entities (father, mother, and son) to two (party and nation)

35 One shot of the Communists, in which they gleefully boast that no Nazi literature is reaching Beusselkietz, intervenes between the two scenes and covers the night during which Heini and Ulla went to the printing shop and completed the printing of the leaflets.

36 In Nazi ideology, it seems that, while Nazism itself stands for a disciplined obedience and the repudiation of full heterosexuality, normal sexuality is prescribed as an equally passive form of moral enslavement.

37 There is a great deal of experimental evidence to show that animals can be taught to learn more rapidly. A new experimental animal will learn only slowly to associate buzzer, lifting the leg, and pain, but the animal with much past experience in experimental settings of this general type will learn to adjust to any particular setting quickly. For a more general discussion of these problems, see Bateson (1942). 


\section{References}

- Bateson, Gregory

1942 National Character and Civilian Morale. In Civilian Morale, Yearbook of the Society for the Psychological Study of Social Issues. New York: Houghton-Mifflin.

- Erikson, Erik

1942 Hitler's Imagery and German Youth. Psychiatry 5:475-493.

- Frank, Lawrence

1939 Time Perspectives. Journal of Social Psychology: 4:293-312.

- Gorer, G.

1943 Some Themes of Japanese Culture. Trans. New York Academy of Science (Feb.).

- Jones, Dorothy B.

Preliminary Report on Motion Picture Content Research Based on an Experimental Group of Twenty-Five Films. Unpublished manuscript.

- Kalbus, Oskar

1935 Vom Werden Deutscher Filmkunst. 2 Teil, CigarettenBilderdienst, Altona-Bahoonfeld, p. 121.

- Kracauer, Siegfried

1942 Propaganda and the Nazi War Film. New York: Museum of Modern Art Film Library.

- Lewin, Kurt

1942 Time Perspective and Morale. In Civilian Morale: Second Yearbook of the Society for the Psychological Study of Social Issues. New York: Houghton-Mifflin.

- Mead, Margaret

1942 And Keep Your Powder Dry. New York: William Morrow. 